\title{
In Operando X-ray Studies of High-Performance Lithium-Ion Storage in Keplerate-Type Polyoxometalate Anodes
}

\author{
Chia-Ching Lin, Chi-Ting Hsu, Wenjing Liu, Shao-Chu Huang, Ming-Hsien Lin, Ulrich Kortz, \\ Ali S. Mougharbel, Tsan-Yao Chen, Chih-Wei Hu, Jyh-Fu Lee, Chun-Chieh Wang, Yen-Fa Liao, \\ Lain-Jong Li, Linlin Li, Shengiie Peng, Ulrich Stimming, and Han-Yi Chen*
}

Cite This: https://dx.doi.org/10.1021/acsami.0c09344

Read Online

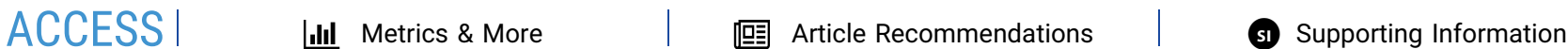

ABSTRACT: Polyoxometalates (POMs) have emerged as potential anode materials for lithium-ion batteries (LIBs) owing to their ability to transfer multiple electrons. Although POM anode materials exhibit notable results in LIBs, their energy-storage mechanisms have not been well-investigated. Here, we utilize various in operando and ex situ techniques to verify the chargestorage mechanisms of a Keplerate-type POM $\mathrm{Na}_{2} \mathrm{~K}_{23}\left\{\left[\left(\mathrm{Mo}^{\mathrm{VI}}\right)\right.\right.$ $\left.\left.\mathrm{MoVI}_{5} \mathrm{O}_{21}\left(\mathrm{H}_{2} \mathrm{O}\right)_{3}\left(\mathrm{KSO}_{4}\right)\right]_{12} \quad\left[\left(\mathrm{~V}^{\mathrm{IV}} \mathrm{O}\right)_{30}\left(\mathrm{H}_{2} \mathrm{O}\right)_{20}\left(\mathrm{SO}_{4}\right)_{0.5}\right]\right\}$. ca200H $\mathrm{H}_{2} \mathrm{O}\left(\left\{\mathbf{M o}_{72} \mathbf{V}_{30}\right\}\right)$ anode in LIBs. The $\left\{\mathbf{M o}_{72} \mathbf{V}_{30}\right\}$ anode provides a high reversible capacity of up to $\sim 1300 \mathrm{~mA} \mathrm{~h} \mathrm{~g}^{-1}$ without capacity fading for up to 100 cycles. The lithium-ion
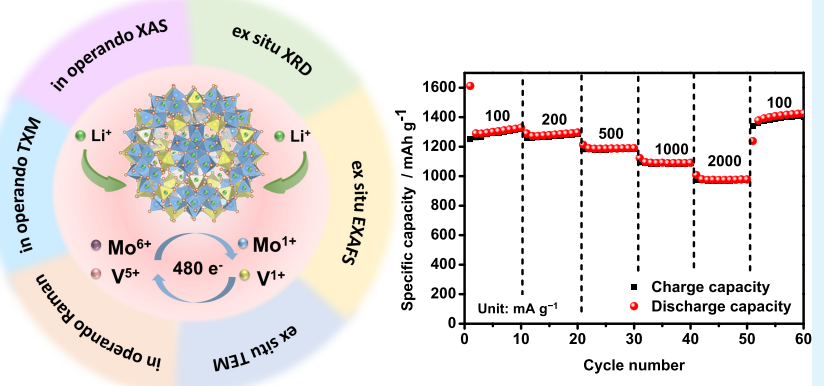
storage mechanism was studied systematically through in operando synchrotron X-ray absorption near-edge structure, ex situ X-ray diffraction, ex situ extended X-ray absorption fine structure, ex situ transmission electron microscopy, in operando synchrotron transmission X-ray microscopy, and in operando Raman spectroscopy. Based on the abovementioned results, we propose that the open hollow-ball structure of the $\left\{\mathbf{M o}_{72} \mathbf{V}_{30}\right\}$ molecular cluster serves as an electron/ion sponge that can store a large number of lithium ions and electrons reversibly via multiple and reversible redox reactions $\left(\mathrm{Mo}^{6+} \leftrightarrow \mathrm{Mo}^{1+}\right.$ and $\left.\mathrm{V}^{5+} / \mathrm{V}^{4+} \leftrightarrow \mathrm{V}^{1+}\right)$ with fast lithium diffusion kinetics $\left(D_{\mathrm{Li}^{+}}: 10^{-9}-10^{-10} \mathrm{~cm}^{2} \mathrm{~s}^{-1}\right)$. No obvious volumetric expansion of the microsized $\left\{\mathbf{M o}_{72} \mathbf{V}_{30}\right\}$ particle is observed during the lithiation/delithiation process, which leads to high cycling stability. This study provides comprehensive analytical methods for understanding the lithium-ion storage mechanism of such complicated POMs, which is important for further studies of POM electrodes in energy-storage applications.

KEYWORDS: polyoxometalate, lithium-ion batteries, electrode, anode materials, charge-storage mechanism

\section{INTRODUCTION}

Lithium-ion batteries (LIBs), which are the most promising energy-storage devices, possess several advantages such as light weight, high energy density (i.e., 150 and $650 \mathrm{~W} \mathrm{~h} \mathrm{~L}^{-1}$ ), ${ }^{1}$ no memory effect, good cycling performance, and low selfdischarge rate, which enable their application in portable electronics and electric vehicles. ${ }^{2}$ Several anode materials have been explored, and they can be divided into three common types based on the energy-storage mechanisms: ${ }^{3}$ (1) intercalation-type (i.e., graphite, ${ }^{4} \mathrm{Li}_{4} \mathrm{Ti}_{5} \mathrm{O}_{12}$ (LTO), ${ }^{5} \mathrm{TiO}_{2}{ }^{6}$ $\mathrm{V}_{2} \mathrm{O}_{5}{ }^{7}$ and $\mathrm{Nb}_{2} \mathrm{O}_{5}^{8}$ ); (2) alloy-type (i.e., $\mathrm{Sn}^{9}$ and Si-based materials); ${ }^{9,10}$ and (3) conversion-type (i.e., $\mathrm{Fe}_{3} \mathrm{O}_{4}{ }^{11} \mathrm{MnO},{ }^{12}$ $\mathrm{MoO}_{2}{ }^{13}$ and $\left.\mathrm{VN}^{14}\right)$. Commercial graphite anodes suffer from low theoretical capacity $\left(\approx 372 \mathrm{~mA} \mathrm{~h} \mathrm{~g}^{-1}\right)$, which severely prevents their applications with high energy demands. ${ }^{15}$ Other anode materials, such as LTO-based materials, that have excellent cycle stability and high charge-discharge rates conversely exhibit low capacity $\left(<200 \mathrm{~mA} \mathrm{~h} \mathrm{~g}^{-1}\right)$, low electrical conductivity, and gassing issues. ${ }^{16}$ Although silicon-based materials have been regarded as some of the most promising anode candidates owing to their superior theoretical capacity $\left(\approx 4200 \mathrm{~mA} \mathrm{~h} \mathrm{~g}^{-1}\right)$, the $\mathrm{Li}-\mathrm{Si}$ alloying process causes a large volume change, which leads to significant performance degradation during cycling. ${ }^{17,18}$ Furthermore, conversion materials exhibit high capacity up to $1000 \mathrm{~mA} \mathrm{~h} \mathrm{~g}^{-1}$; however, volume expansion results in severe capacity fading.

Polyoxometalates (POMs) are known as a class of anionic polynuclear transition-metal oxides, and they have emerged as potential electrode materials for energy-storage devices such as LIBs, sodium-ion batteries, and supercapacitors owing to their ability to undergo fast redox reactions and transfer multiple electrons per molecule. ${ }^{19-22}$ Several POMs and POM-based

Received: May 22, 2020

Accepted: August 12, 2020 
composites have been studied as anodes for LIBs, which exhibit high reversible capacities ranging from 286 to $1300 \mathrm{~mA}$ $\mathrm{h} \mathrm{g}^{-1}$.22-33 Among these POM anode materials, Mo-based POMs exhibit superior battery performance. Li et al. reported a composite that combined a Mo-based Anderson-type POM, $\mathrm{Na}_{3}\left[\mathrm{AlMo}_{6} \mathrm{O}_{24} \mathrm{H}_{6}\right]$ (NAM), with ethylenediamine-functionalized reduced graphene oxide (EDAG) as anodes for LIBs. ${ }^{27}$ The NAM-EDAG anode delivered a high reversible capacity of up to $1000 \mathrm{~mA} \mathrm{~h} \mathrm{~g}^{-1}$ for more than 100 cycles with a high Coulombic efficiency $(\sim 100 \%)$ as well as excellent cycling and rate performance. It showed that Mo ions in NAM were reduced to the $\mathrm{Mo}^{0}$ metal phase after discharging to $0 \mathrm{~V}$ while they were reoxidized to $\mathrm{Mo}^{6+}$ after charging to $3 \mathrm{~V}$ by ex situ Xray photoelectron spectroscopy (XPS) analyses, indicating that NAM can serve as a conversion anode with six electron transfers per Mo ion. ${ }^{27} \mathrm{Li}$ et al. proposed that the lithium ions can move between molecular-sized units and increase the conversion efficiency owing to the cluster-like framework of POMs, which leads to a conversion reaction with much higher capacity than $\mathrm{MoO}_{3}$ and with more compact $\mathrm{MoO}_{6}$ linkage. ${ }^{27}$ Song and Streb et al. utilized a sonication-driven strategy to prepare $1 \mathrm{D}$ periodically patterned TBA- $\mathrm{PMo}_{11} \mathrm{~V} / \mathrm{CNT}$ (TBA $=\left[\mathrm{N}\left(\mathrm{CH}_{2} \mathrm{CH}_{2} \mathrm{CH}_{2} \mathrm{CH}_{3}\right)_{4}\right]^{+} ; \mathrm{PMo}_{11} \mathrm{~V}:\left[\mathrm{PMo}_{11} \mathrm{VO}_{40}\right]^{4-} ; \mathrm{CNT}$ : carbon nanotube) composites which provided discharge capacities of $850 \mathrm{~mA} \mathrm{~h} \mathrm{~g}^{-1}$ at $0.5 \mathrm{~mA} \mathrm{~cm}{ }^{-2}$ after 100 cycles. $^{34}$ Lan et al. synthesized three Mo-based POM composites with different molecular structures: EMI-PMo ${ }_{12} @ \mathrm{rGO}$, EMI$\mathrm{Mo}_{72} \mathrm{~V}_{30} @ \mathrm{rGO}$, and EMI-Mo ${ }_{132} @ \mathrm{rGO}$ (EMI: 1-ethyl-3methylimidazolium; $\mathrm{PMo}_{12}:\left[\mathrm{PMo}_{12} \mathrm{O}_{40}\right]^{3-}$ (Keggin-type cluster); $\mathrm{Mo}_{72} \mathrm{~V}_{30}: \quad\left[\mathrm{K}_{14}\left[\mathrm{~K}_{10} \subset\left\{\left(\mathrm{Mool}^{\mathrm{VI}}\right)\right.\right.\right.$ $\left.\left.\left.\mathrm{Mo}_{5}{ }_{5} \mathrm{O}_{21}\left(\mathrm{H}_{2} \mathrm{O}\right)_{3}\left(\mathrm{SO}_{4}\right)\right\}_{12}\left\{\left(\mathrm{~V}^{\mathrm{IV}} \mathrm{O}\right)_{30}\left(\mathrm{H}_{2} \mathrm{O}\right)_{20}\right\}\right]\right]^{20-}$ (Keplerate-type hollow-ball structure); $\mathrm{Mo}_{132}$ : $\left[\left(\mathrm{NH}_{4}\right)_{20}\left[\mathrm{Mo}^{\mathrm{VI}}{ }_{72} \mathrm{Mo}^{\mathrm{V}}{ }_{60} \mathrm{O}_{372}\left(\mathrm{CH}_{3} \mathrm{COO}\right)_{30}\left(\mathrm{H}_{2} \mathrm{O}\right)_{72}\right]\right]^{22-}$ (Keplerate-type hollow-ball structure); and rGO: reduced graphene oxide) and studied the effect of the molecular structure on lithium-ion storage performance. Among these composites, EMI-Mo $\mathrm{M}_{72} \mathrm{~V}_{30} @ \mathrm{rGO}$ delivers a high reversible capacity of 1145 $\mathrm{mA} \mathrm{h} \mathrm{g}{ }^{-1}$ at $100 \mathrm{~mA} \mathrm{~g}^{-1}$, with an excellent capacity retention (ca. $100 \%$ after 500 cycles). It was suspected that the large void space and surface area of the hollow-structured $\mathrm{Mo}_{72} \mathrm{~V}_{30}$ might effectively accommodate the lithium ions and buffer the volume expansion; however, the charge-storage mechanism of the key active material $\mathrm{Mo}_{72} \mathrm{~V}_{30}$ is not clearly understood or proved and that is fundamentally important and urgently required for further utilization and design of high-performance batteries based on such a high-capacity anode.

Here, in this study, we first reported the lithium-ion storage mechanis m of $\mathrm{Na}_{2} \mathrm{~K}_{23}\left\{\left[\left(\mathrm{M} \mathrm{ovI}^{\mathrm{VI}}\right)\right.\right.$ $\left.\left.\mathrm{Mo}_{5}{ }_{5} \mathrm{O}_{21}\left(\mathrm{H}_{2} \mathrm{O}\right)_{3}\left(\mathrm{KSO}_{4}\right)\right]_{12}\left[\left(\mathrm{~V}^{\mathrm{IV}} \mathrm{O}\right)_{30}\left(\mathrm{H}_{2} \mathrm{O}\right)_{20}\left(\mathrm{SO}_{4}\right)_{0.5}\right]\right\}$. ca200 $\mathrm{H}_{2} \mathrm{O},\left\{\mathbf{M o}_{72} \mathbf{V}_{30}\right\}$, by various in operando methods. $\left\{\mathbf{M o}_{72} \mathbf{V}_{30}\right\}$ is a Keplerate-type metal oxide cluster with a diameter of $2.1 \mathrm{~nm}$ that is constructed with $12\left\{\left(\mathrm{Mo}^{\mathrm{VI}}\right) \mathrm{Mo}_{5}{ }_{5}\right\}$ pentagonal bipyramids and $30\left\{\mathrm{~V}^{\mathrm{IV}} \mathrm{O}\right\}$ as linkers, as shown in Figure 1. It has 20 open pore windows on the hollow-ball structure, which is beneficial for lithium-ion transportation. We revealed that a large amount of $\mathrm{Mo}$ and $\mathrm{V}$ ions with high oxidation states in the $\left\{\mathbf{M o}_{72} \mathbf{V}_{30}\right\}$ molecular cluster allow for multiple redox reactions, leading to its high capacity. The electrochemical properties were carefully studied and the lithium-ion storage mechanism of $\left\{\mathbf{M o}_{72} \mathbf{V}_{30}\right\}$ anodes was clarified with various in operando/ex situ characterization techniques, including in operando synchrotron X-ray absorption near-edge structure (XANES), ex situ X-ray diffraction

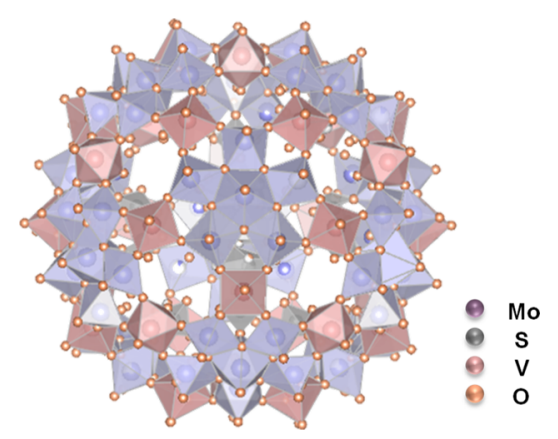

Figure 1. Polyhedral representation for the structure of the Kepleratetype $\left\{\mathbf{M o}_{72} \mathbf{V}_{30}\right\}$ polyanion.

(XRD), ex situ extended X-ray absorption fine structure (EXAFS), ex situ transmission electron microscopy (TEM), in operando synchrotron transmission X-ray microscopy (TXM), and in operando Raman spectroscopy. The lithium-ion diffusivity was also evaluated via potentiostatic intermittent titration technique (PITT) measurements. These techniques are utilized to study the structural and morphological evolutions, the interfacial change between the electrode and electrolyte, and the dynamic process involved during lithiation/delithiation processes. This work provides insights into the charge-storage mechanism for such complicated POMs through comprehensive analysis techniques, which are important for further studies of POM electrodes in energystorage applications.

\section{EXPERIMENTAL SECTION}

2.1. Synthesis of $\left\{\mathrm{Mo}_{72} \mathrm{~V}_{30}\right\} . \mathrm{Na}_{2} \mathrm{~K}_{23}\left\{\left[\left(\mathrm{Mo}^{\mathrm{VI}}\right)\right.\right.$ $\left.\left.\mathrm{Mo}_{5}{ }_{5} \mathrm{O}_{21}\left(\mathrm{H}_{2} \mathrm{O}\right)_{3}\left(\mathrm{KSO}_{4}\right)\right]_{12} \quad\left[\left(\mathrm{~V}^{\mathrm{IV}} \mathrm{O}\right)_{30}\left(\mathrm{H}_{2} \mathrm{O}\right)_{20}\left(\mathrm{SO}_{4}\right)_{0.5}\right]\right\}$. ca2 $200 \mathrm{H}_{2} \mathrm{O},\left\{\mathbf{M o}_{72} \mathbf{V}_{30}\right\}$, was synthesized by a facile solution process as described in the literature. ${ }^{35}$ First, VOSO $_{4} \cdot 5 \mathrm{H}_{2} \mathrm{O}(2.53 \mathrm{~g}, 10$ mmol) was dissolved in $35 \mathrm{~mL} \mathrm{H}_{2} \mathrm{O}$, and the solution was then added to a conical flask with $8 \mathrm{~mL}$ of $0.5 \mathrm{M} \mathrm{H}_{2} \mathrm{SO}_{4}$ solution mixed with $\mathrm{Na}_{2} \mathrm{MoO}_{4} \cdot 2 \mathrm{H}_{2} \mathrm{O}(2.42 \mathrm{~g}, 10 \mathrm{mmol})$. The conical flask with the abovementioned dark purple mixture was sealed using a rubber stopper and stirred at room temperature for $30 \mathrm{~min} . \mathrm{KCl}(0.65 \mathrm{~g}, 8.72$ mmol) was then added to the mixture, which was stirred for another $30 \mathrm{~min}$. The obtained solution was kept in the flask with a rubber stopper for 5 days; purple-black $\left\{\mathbf{M o}_{72} \mathbf{V}_{30}\right\}$ crystals were obtained by filtration. After washing with cold water, the final products were dried under air, and the yield was $\sim 1 \mathrm{~g}$. Elemental analysis $\%$ calcd (found): H 2.6 (2.0); Inductively coupled plasma (ICP) analysis \% calcd (found): V 8.55 (8.5), S 2.02 (1.8), Mo 36.0 (36.2), K 4.92 (4.9), Na 0.96 (1); $\mathrm{M}=20,009.48 \mathrm{~g} / \mathrm{mol}$.

2.2. Material Characterization. A Fourier transform infrared spectroscopy (FT-IR) spectrophotometer (Nicolet Avatar 370) was utilized to detect the infrared spectra of $\left\{\mathbf{M o}_{72} \mathbf{V}_{30}\right\}$ using $\mathrm{KBr}$ pellets and repeatedly scanned over the range of $4000-400 \mathrm{~cm}^{-1}$. The identity of $\left\{\mathbf{M o}_{72} \mathbf{V}_{30}\right\}$ was also established using the UV-vis spectrum, obtained using a UV-vis spectrophotometer (Varian Cary 5000). The thermogravimetric analysis (TGA) measurement of $\left\{\mathbf{M o}_{72} \mathbf{V}_{30}\right\}$ was recorded using a thermal analyzer (STA $449 \mathrm{~F} 1$ Jupiter) under $20 \mathrm{~mL} \mathrm{~min}^{-1}$ flow of argon and the temperature was increased from 25 to $800{ }^{\circ} \mathrm{C}$ at a rate of $5{ }^{\circ} \mathrm{C} \mathrm{min}{ }^{-1}$. The surface morphology of $\left\{\mathbf{M o}_{72} \mathbf{V}_{30}\right\}$ was characterized by field emission SEM (FESEM, Hitachi SU8010). The Bruker D2 Phaser X-ray diffractometer was used to characterize the crystal structure of $\left\{\mathbf{M o}_{72} \mathbf{V}_{30}\right\}$ by XRD measurement. Further details on the crystal structure investigation of $\left\{\mathbf{M o}_{72} \mathbf{V}_{30}\right\}$ can be obtained from the Fachinformationszentrum Karlsruhe, 76344 Eggenstein-Leopoldshafen (Germany), on quoting the depository number CSD-433790. Elemental analyses were performed using the Elementar Analysensysteme vario EL III instrument. Raman microscopy (Labram HR800) with a 514 
(a)
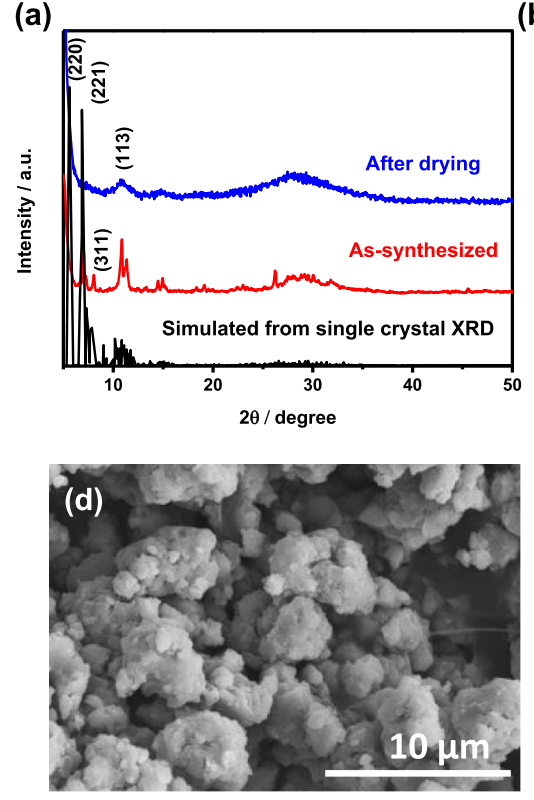

(b)

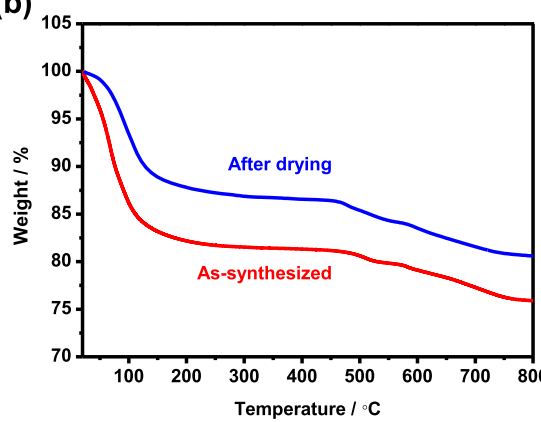

(e)

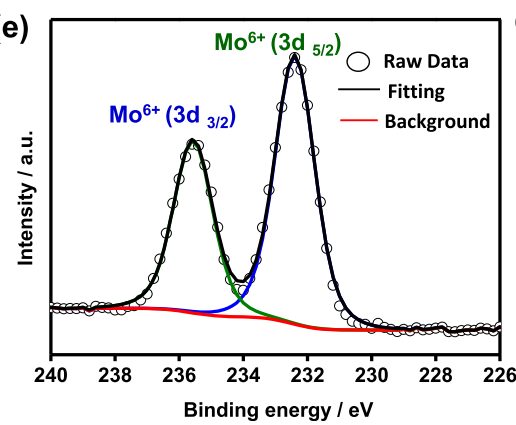

(c)
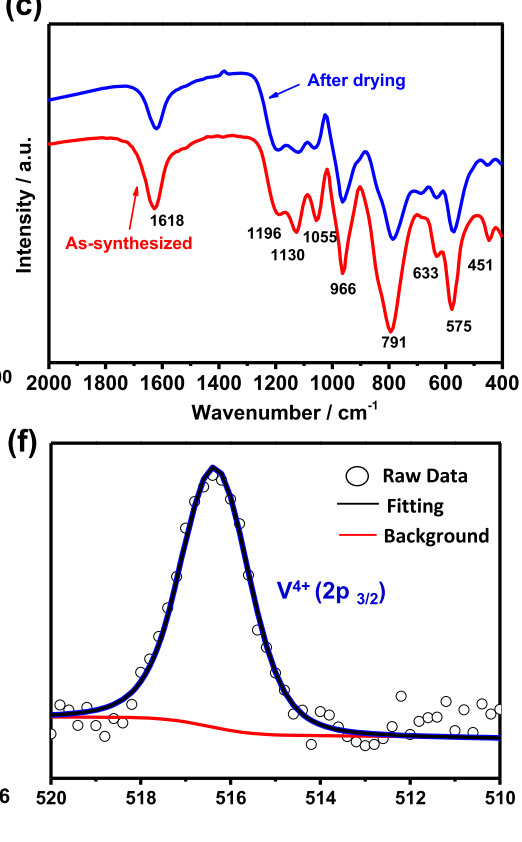

Figure 2. (a) XRD patterns, (b) TGA spectra, and (c) FT-IR spectra of $\left\{\mathbf{M o}_{72} \mathbf{V}_{30}\right\}$ before and after drying treatment; (d) FESEM image, (e) Mo XPS spectrum, and (f) V XPS spectrum of $\left\{\mathbf{M o}_{72} \mathbf{V}_{30}\right\}$ after drying treatment.

$\mathrm{nm}$ excitation laser was employed to record the Raman spectra of $\left\{\mathbf{M o}_{72} \mathbf{V}_{30}\right\}$. The direct current polarization was measured using a BioLogic potentiostat VMP3 at $3 \mathrm{~V}$ within a $\left\{\mathbf{M o}_{72} \mathbf{V}_{30}\right\}$ pellet-coated $\mathrm{Pt}$ at the surface. The surface area of $\left\{\mathbf{M o}_{72} \mathbf{V}_{30}\right\}$ was determined by the Brunauer-Emmett-Teller (BET) analysis from the $\mathrm{N}_{2}$ adsorption-desorption isotherms obtained at $77 \mathrm{~K}$ implemented using the ASAP2020 instrument (Micrometric Corp.).

2.3. Battery Preparation and Characterization. The active layers of anodes were prepared by mixing $\left\{\mathbf{M o}_{72} \mathbf{V}_{30}\right\}$, carbon black (Super P), and sodium carboxymethyl cellulose (CMC) as a binder in DI water with a weight ratio of 70:20:10. Then, it was coated on $\mathrm{Cu}$ foil and dried under $80{ }^{\circ} \mathrm{C}$ overnight. After drying, the coating was punched into pieces with a diameter of $13.7 \mathrm{~mm}$ and then rollpressed, followed by drying at $110{ }^{\circ} \mathrm{C}$ under vacuum for $4 \mathrm{~h}$. The mass loading of the active material is about $1-2 \mathrm{mg} \mathrm{cm}^{-2}$; CR2032 coin cells were prepared under an argon atmosphere in a glovebox. The $\left\{\mathbf{M o}_{72} \mathbf{V}_{30}\right\}$ anode was tested in a half-cell configuration with the $\mathrm{Li}$ foil as the counter and reference electrodes. LIB cells were assembled in a liquid electrolyte consisting of $1 \mathrm{M} \mathrm{LiPF}_{6}$ in a mixture of ethylene carbonate (EC) and diethyl carbonate (DEC) with a volume ratio of $1: 1$, in which $10 \mathrm{wt} \%$ fluoroethylene carbonate (FEC) was added as an electrolyte additive and they were separated by a Celgard 2500 battery membrane. Cyclic voltammetry (CV) and galvanostatic charge/discharge (GCD) measurements were carried out in a voltage range of $0.01-3 \mathrm{~V}$ versus $\mathrm{Li} / \mathrm{Li}^{+}$. The specific lithiation/delithiation capacities were calculated based on the weight of the anode active material. High-resolution XPS (HR-XPS, ESCA ULVAC-PHI PHI 5000 Versaprobe II) with an Al $\mathrm{k} \alpha$ source was performed to characterize the Mo and $\mathrm{V}$ bonding states of pristine and cycled electrodes for $\left\{\mathbf{M o}_{72} \mathbf{V}_{30}\right\}$ half-cells. The ex situ XRD patterns of $\left\{\mathbf{M o}_{72} \mathbf{V}_{30}\right\}$ electrodes were detected using the Bruker D2 phaser X-ray diffractometer. In operando Mo K-edge XANES was performed using a CR2032 coil cell with a hole in the center, which was taped with Kapton, under the fluorescent mode at beamline SP12B1 at Spring 8, Hyogo Prefecture, Japan. The in operando V Kedge was measured through a pouch cell with a hole, which was taped with Kapton, under the fluorescent mode at beamline TLS 17C1 at National Synchrotron Radiation Research Center (NSRRC) in Taiwan. The XANES data were processed by utilizing the Athena 0.8.056/IFEFFIT 1.2.11 software. Ex situ Mo K-edge EXAFS was measured through utilizing the scraped off powder-like active material from the electrode, which was sealed with Kapton tape, under the transmission mode at beamline TPS 44A1 at NSRRC in Taiwan. The loading mass of the active material on the electrode was about $1 \mathrm{mg}$ $\mathrm{cm}^{-2}$, and the Mo content in the electrode was approximately $40 \%$; thus, the calculated edge jump $(\Delta \mu x)$ was around 0.03 , which was too low to be detected through the transmission mode. Therefore, we conducted the in operando Mo K-edge XANES under the fluorescent mode. The EXAFS data were analyzed using the Artemis (version 0.9.26) software. The in operando Raman spectroscopy measurements were performed by employing a CR2032 coin cell with quartz windows using a Raman microscope (UniDRON system) with a $530.9 \mathrm{~nm}$ excitation laser and $1 \mathrm{~mW}$ power. Ex situ TEM was performed using JEOL, JEM-ARM200FTH. In operando TXM was also performed using a CR2032 coin cell with a hole, as mentioned above, at beamline TLS 01B1 at NSRRC in Taiwan. The focused Xrays illuminated the electrode in the coin cell through a capillary condenser. Then, a Fresnel zone plate was used to record high-spatialresolution transmission X-ray images, which were captured using a $\mathrm{CCD}$ camera. After the zone plate, a phase ring was installed at the back focal plane of the zone plate to increase image contrast by optical phase differences. A GCD test was carried out on the in operando coin cells at a current density of $100 \mathrm{~mA} \mathrm{~g}^{-1}$ and within a voltage range of $0.01-3 \mathrm{~V}$ versus $\mathrm{Li} / \mathrm{Li}^{+}$. A PITT test was measured on the BioLogic potentiostat VMP3 with the potential step of $25 \mathrm{mV}$ and the holding time of $3600 \mathrm{~s}$ at each state. The electrodes assembled in the CR2032 cells were discharged from OCV to $0.01 \mathrm{~V}$ versus $\mathrm{Li} / \mathrm{Li}^{+}$. The electrochemical impedance spectroscopy (EIS) measurement was measured on the BioLogic potentiostat VMP3 at OCV, 0.01, and $3 \mathrm{~V}$ versus $\mathrm{Li} / \mathrm{Li}^{+}$from $1 \mathrm{MHz}$ to $10 \mathrm{mHz}$.

\section{RESULTS}

3.1. Material Characterization. $\left\{\mathbf{M o}_{72} \mathbf{V}_{30}\right\}$ was synthesized by a facile solution process and characterized with the UV-vis spectrum, Raman spectroscopy, single-crystal and powder XRD, TGA, FT-IR, scanning electron microscopy (SEM), and XPS. The vibration peaks of $\left\{\mathbf{M o}_{72} \mathbf{V}_{30}\right\}$ are presented in the Raman spectrum $\left(\lambda_{\mathrm{e}}: 514 \mathrm{~nm}\right)$ at $941(\mathrm{w}$, $\nu(\mathrm{V}=\mathrm{O}) / \nu(\mathrm{Mo}=\mathrm{O}))$ and $872\left(\mathrm{~s}, \mathrm{~A}_{1 \mathrm{~g}} \mathrm{O}_{\mathrm{br}}\right) \mathrm{cm}^{-1}$, as shown in Figure S1a. Figure $\mathrm{S} 1 \mathrm{~b}$ presents the $\mathrm{UV}-$ vis spectrum of $\left\{\mathbf{M o}_{72} \mathbf{V}_{30}\right\}$ in $\mathrm{H}_{2} \mathrm{O}$ and the absorption bands observed at 512 

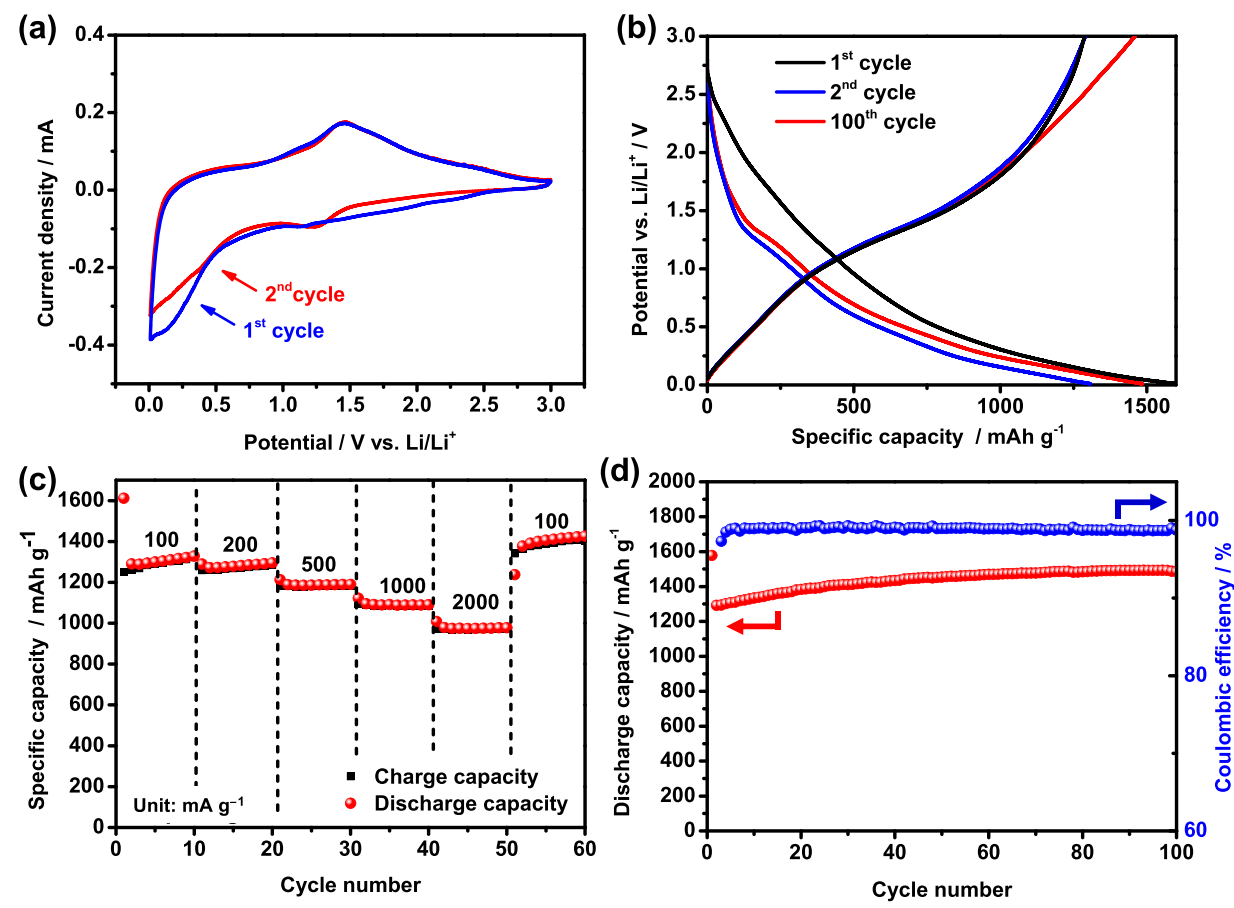

Figure 3. Electrochemical performance of $\left\{\mathbf{M o}_{72} \mathbf{V}_{30}\right\}$ anode in $1 \mathrm{M} \mathrm{LiPF}_{6} / \mathrm{EC}$ DEC:FEC (45:45:10) in a half-cell configuration with Li metal as the counter electrode and reference electrode in a potential range of $0.01-3 \mathrm{~V} \mathrm{vs} \mathrm{Li}^{+} / \mathrm{Li}$ : (a) cyclic voltammograms at a scan rate of $0.1 \mathrm{mV} \mathrm{s}{ }^{-1}$; $(\mathrm{b})$ GCD curves at a current density of $100 \mathrm{~mA} \mathrm{~g}^{-1}$; (c) rate performance at various current densities; (d) cycling performance and the Coulombic efficiency at current density of $100 \mathrm{~mA} \mathrm{~g}^{-1}$.

(vs), $690(\mathrm{w})$, and $846(\mathrm{w}) \mathrm{nm}$ are similar to those in previous studies. $^{35}$ The powder XRD pattern of the as-synthesized $\left\{\mathbf{M o}_{72} \mathbf{V}_{30}\right\}$ is shown in Figure $2 \mathrm{a}$, and the reflections of the assynthesized $\left\{\mathbf{M o}_{\mathbf{7 2}} \mathbf{V}_{\mathbf{3 0}}\right\}$ agree with the one simulated from its single-crystal XRD data (CSD-433790, presented in Table S1). The as-synthesized $\left\{\mathbf{M o}_{72} \mathbf{V}_{30}\right\}$ was heated to $80{ }^{\circ} \mathrm{C}$ overnight before preparing the electrodes for coin cell assembling. Almost all reflections for the as-synthesized $\left\{\mathbf{M o}_{72} \mathbf{V}_{30}\right\}$ after drying at $80{ }^{\circ} \mathrm{C}$ overnight disappeared except for the reflections at $11^{\circ}$. This indicates that the long-term crystal structure of $\left\{\mathbf{M o}_{72} \mathbf{V}_{30}\right\}$ becomes amorphous by removing crystal water after drying, and this phenomenon can also be observed from other POM electrodes in the literature. ${ }^{21,36}$ Figure $2 \mathrm{~b}$ displays the TGA data of $\left\{\mathbf{M o}_{72} \mathbf{V}_{30}\right\}$. The weight loss below $200{ }^{\circ} \mathrm{C}$ is the evaporation of crystal water, and the weight loss after $600{ }^{\circ} \mathrm{C}$ indicates the decomposition of $\left\{\mathbf{M o}_{72} \mathbf{V}_{30}\right\}$. The amount of crystal water decreases after the drying treatment, as detected by TGA. Figure $2 \mathrm{c}$ shows the FT-IR spectrum of the as-synthesized $\left\{\mathbf{M o}_{72} \mathbf{V}_{30}\right\}$, which exhibits the characteristic absorption bands: $\nu=1618(\mathrm{~m})$, $\left(\delta\left(\mathrm{H}_{2} \mathrm{O}\right)\right) 1196(\mathrm{w}), 1130(\mathrm{w}), 1055(\mathrm{w})\left(\nu_{\mathrm{as}}\left(\mathrm{SO}_{4}\right)\right.$ triplet $)$, $966(\mathrm{~s})(\nu(\mathrm{V}=\mathrm{O}) / \nu(\mathrm{Mo}=\mathrm{O})), 791(\nu \mathrm{s}), 633(\mathrm{w}), 575(\mathrm{~s})$, and $451(\mathrm{w})\left(\delta(\mathrm{Mo}-\mathrm{O}-\mathrm{Mo}) / \nu_{\mathrm{as}}(\mathrm{Mo}-\mathrm{O}-\mathrm{Mo})\right) \mathrm{cm}^{-1}$, as reported in the literature. ${ }^{35}$ After the drying treatment, the characteristic absorption bands remain unchanged indicating that the structure of the $\left\{\mathbf{M o}_{72} \mathbf{V}_{30}\right\}$ polyanion is unchanged. Figure $2 \mathrm{~d}$ displays the SEM image of $\left\{\mathbf{M o}_{72} \mathbf{V}_{30}\right\}$ powders that shows irregular shape, and the particle size is around several micrometers. The Mo $3 \mathrm{~d}$ and $\mathrm{V} 2 \mathrm{p}$ XPS spectrum of $\left\{\mathbf{M o}_{72} \mathbf{V}_{30}\right\}$ powders is shown in Figure 2e,f. The oxidation states of $\left\{\mathbf{M o}_{72} \mathbf{V}_{30}\right\}$ after drying treatment are $\mathrm{Mo}^{6+}\left(3 \mathrm{~d}_{3 / 2}\right.$ binding energy of $235.6 \pm 0.2 \mathrm{eV}$ and $3 \mathrm{~d}_{5 / 2}$ of $232.4 \pm 0.2 \mathrm{eV}$ ) and $\mathrm{V}^{4+}\left(2 \mathrm{p}_{3 / 2}\right.$ binding energy of $\left.516.2 \pm 0.2 \mathrm{eV}\right)$, as reported in the literature. ${ }^{37,38}$ The direct current polarization test was implemented to estimate the electronic conductivity of $\left\{\mathbf{M o}_{\mathbf{7 2}} \mathbf{V}_{\mathbf{3 0}}\right\}$ through the Hebb-Wagner polarization method, ${ }^{39}$ as shown in Figure S1c. The electronic conductivity of $\left\{\mathbf{M o}_{72} \mathbf{V}_{30}\right\}$ is about $2.65 \times 10^{-7} \mathrm{~S} \mathrm{~cm}^{-1}$ which is higher than that of the commercial LTO anode $\left(10^{-8}-10^{-13} \mathrm{~S} \mathrm{~cm}^{-1}\right)^{40,41}$ but lower than that of graphite $\left(9.5 \times 10^{-1} \mathrm{~S} \mathrm{~cm}^{-1}\right){ }^{42}$ Figure S1d shows the $\mathrm{N}_{2}$ adsorption-desorption isotherms for $\left\{\mathbf{M o}_{72} \mathbf{V}_{30}\right\}$ powder, and the BET surface area is around 0.19 $\mathrm{cm}^{2} \mathrm{~g}^{-1}$.

3.2. Electrochemical Characterization. To understand the electrochemical performance of $\left\{\mathbf{M o}_{72} \mathbf{V}_{30}\right\}$ as an anode material for LIBs, CV and GCD measurements were employed in a half-cell configuration. The half-cells were first lithiated from the open-circuit voltage (OCV) to $0.01 \mathrm{~V}$ versus $\mathrm{Li} / \mathrm{Li}^{+}$ and subsequently, they cycled between 0.01 and $3 \mathrm{~V}$ versus $\mathrm{Li} /$ $\mathrm{Li}^{+}$. The CV curves of $\left\{\mathbf{M o}_{72} \mathbf{V}_{30}\right\}$ anodes were carried out at a scan rate of $0.1 \mathrm{mV} \mathrm{s}^{-1}$, as shown in Figure $3 \mathrm{a}$. The higher reduction current in the first cycle of the $\mathrm{CV}$ curves as compared to the second cycle in the range of $0.01-0.5 \mathrm{~V}$ might be attributed to the formation of solid-electrolyte interphase (SEI) and irreversible insertion. ${ }^{43}$ The insertion of $\mathrm{Li}^{+}$into $\left\{\mathbf{M o}_{72} \mathrm{~V}_{30}\right\}$ can be observed in the range of $0.3-1.3 \mathrm{~V}$ and at the reduction peak of $\sim 0.01 \mathrm{~V}$ versus $\mathrm{Li} / \mathrm{Li}^{+}$. The broad region in the oxidation curve range from 0.75 to $2.0 \mathrm{~V}$ versus $\mathrm{Li} / \mathrm{Li}^{+}$could be contributed from the deinsertion of $\mathrm{Li}^{+}$from $\left\{\mathbf{M o}_{72} \mathbf{V}_{30}\right\}$. The broad potential range for $\mathrm{Li}^{+}$insertion/ extraction in the $\mathrm{CV}$ curve can be ascribed to the random distribution of free spaces in the highly disordered structures of $\left\{\mathbf{M o}_{72} \mathbf{V}_{30}\right\}$ and the continuous redox reactions by the multiple redox centers in one molecule.

Figure $3 \mathrm{~b}$ displays GCD profiles of $\left\{\mathbf{M o}_{72} \mathbf{V}_{30}\right\}$ as an anode in a half-cell configuration at a current density of $100 \mathrm{~mA} \mathrm{~g}^{-1}$ in the $1 \mathrm{st}, 2 \mathrm{nd}$, and 100 th cycles. It shows a steady curve with several obscure plateaus in the potential range between 0.01 

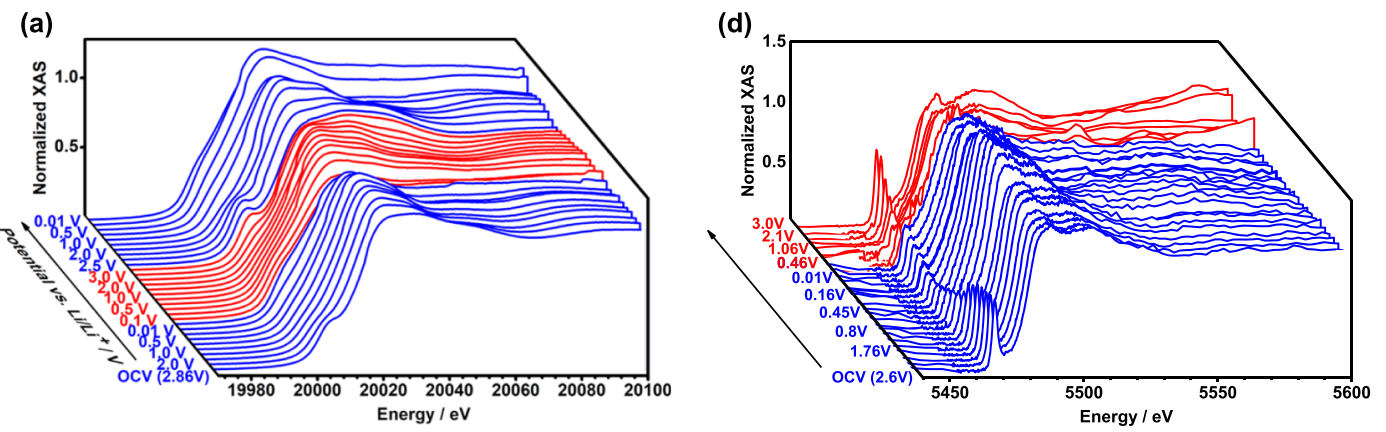

(b)

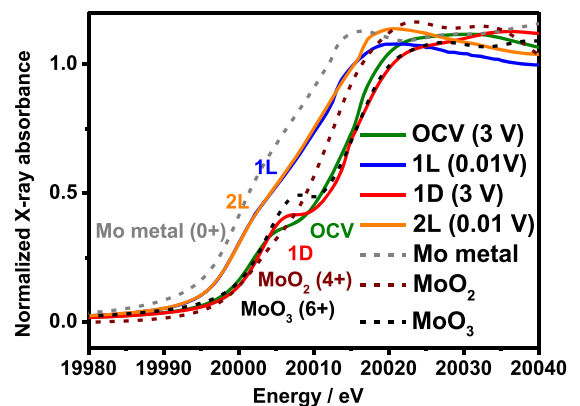

(c)

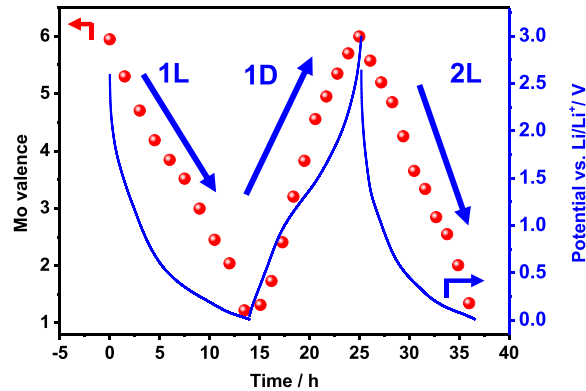

(e)

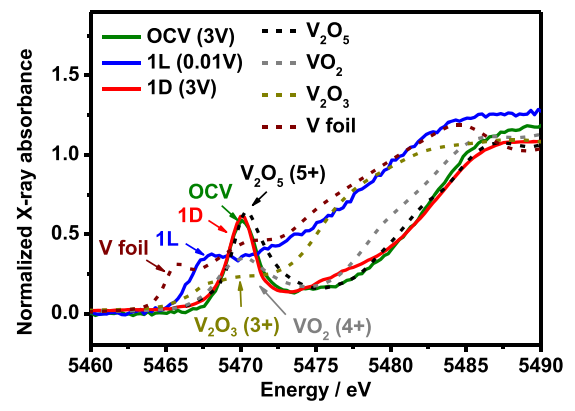

(f)

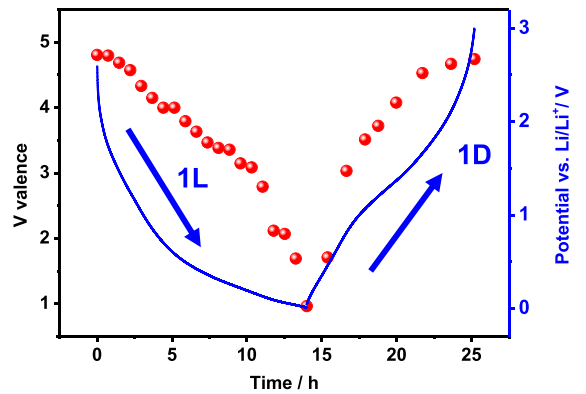

Figure 4. (a) Normalized in operando synchrotron Mo K-edge XANES spectra of $\left\{\mathrm{Mo}_{72} \mathrm{~V}_{30}\right\}$ measured at different potentials vs Li/Li ${ }^{+}$at a current density of $100 \mathrm{~mA} \mathrm{~g}^{-1}$ (blue: the lithiation process; red: the delithiation process). (b) Normalized in operando synchrotron Mo K-edge XANES spectra of $\left\{\mathbf{M o}_{72} \mathbf{V}_{30}\right\}$ in the first cycle at a potential of OCV $(2.86 \mathrm{~V})$, the first full lithiation $(1 \mathrm{~L}, 0.01 \mathrm{~V})$, the first full delithiation (1D, $\left.3 \mathrm{~V}\right)$, and the second full lithiation (2L, $0.01 \mathrm{~V}$ ), compared with $\mathrm{MoO}_{3}, \mathrm{MoO}_{2}$, and Mo metal foil reference materials. (c) Average Mo valence of $\left\{\mathbf{M o}_{72} \mathrm{~V}_{30}\right\}$ as a function of the potential. (d) Normalized in operando synchrotron V K-edge XANES spectra of $\left\{\mathbf{M o}_{72} \mathbf{V}_{30}\right\}$. (e) Normalized in operando synchrotron V K-edge XANES spectra of OCV, 1L, and $1 \mathrm{C}$ compared with $\mathrm{V}_{2} \mathrm{O}_{5}, \mathrm{VO}_{2}, \mathrm{~V}_{2} \mathrm{O}_{3}$, and $\mathrm{V}$ metal foil. (f) Average $\mathrm{V}$ valence of $\left\{\mathbf{M o} \mathbf{o}_{72} \mathrm{~V}_{30}\right\}$ as a function of the potential.

and $2.5 \mathrm{~V}$ versus $\mathrm{Li} / \mathrm{Li}^{+}$indicating the combination of intercalation and capacitive-like storage behaviors with the continuous insertion of $\mathrm{Li}$ ions. This results in a high reversible capacity up to ca. $1300 \mathrm{~mA} \mathrm{~h} \mathrm{~g}{ }^{-1}$, which is contributed from the multiple redox centers in $\left\{\mathbf{M o}_{72} \mathbf{V}_{30}\right\}$. This value is much higher than the commonly used intercalation-type anode materials, for example, graphite (theoretical capacity $\approx 372 \mathrm{~mA}$ $\mathrm{h} \mathrm{g}^{-1}$ ) and LTO (100-200 $\mathrm{mA} \mathrm{h} \mathrm{g}^{-1}$ ). The lithiation curve of $\left\{\mathbf{M o}_{72} \mathbf{V}_{30}\right\}$ showed a nonobvious lithiation platform for the first cycle. However, it exhibited an obvious and consistent lithiation platform at $1.25 \mathrm{~V}$ in the $2 \mathrm{nd}$ and 100th cycle. It was owing to the activation process after the initial few cycles. The $\mathrm{Li}$ ion can insert into $\left\{\mathbf{M o}_{72} \mathbf{V}_{30}\right\}$ molecules more easily after the activation process thus the capacity increased. This activation process can be confirmed by the increase in the Li-ion diffusion coefficient after several cycles, which will be discussed later in the kinetic process analyses. Figure S2 shows the $\mathrm{dQ} / \mathrm{dV}$ versus voltage plots derived from the GCD profiles. The high $\mathrm{dQ} / \mathrm{d} V$ value in the 100th cycle compared to the 2 nd cycle can be observed in the range of $0.01-2 \mathrm{~V}$ (lithiation process) and 1.5-3 $\mathrm{V}$ (delithiation process). Because there is no extra characteristic peak generated, the increase in capacity during the first 100 cycles is contributed by the surface adsorption or the continuous intercalation. The reduction peak of the $\mathrm{d} Q / \mathrm{d} V$ plot at $1.25 \mathrm{~V}$ shifts to the higher potential after 100 cycles, indicating the increase in the Li-ion diffusion coefficient. This phenomenon will also be discussed later. Figure $3 c$ displays the rate performance at different current densities from 100 to $2000 \mathrm{~mA} \mathrm{~g}^{-1}$. The average specific capacities are approximately 1290, 1273, 1187, 1098, and 979 $\mathrm{mA} \mathrm{h} \mathrm{g}^{-1}$ at current densities of 100, 200, 500, 1000, and 2000 $\mathrm{mA} \mathrm{g}{ }^{-1}$, respectively, suggesting that the $\left\{\mathbf{M o}_{72} \mathbf{V}_{30}\right\}$ anode can provide good rate performance. The cycling performance of the $\left\{\mathbf{M o}_{72} \mathbf{V}_{30}\right\}$ anode in LIB at a current density of $100 \mathrm{~mA} \mathrm{~h}$ $\mathrm{g}^{-1}$ is shown in Figure $3 \mathrm{~d}$. The first lithiation and delithiation capacities are 1578 and $1292 \mathrm{~mA} \mathrm{~h} \mathrm{~g}^{-1}$, respectively, with the Coulombic efficiency of around $81.8 \%$. The first irreversible capacity might be attributed to the formation of SEI. ${ }^{43}$ After 100 cycles, the capacity slightly increased from 1292 (the second reversible discharge capacity) to $1495 \mathrm{~mA} \mathrm{~h} \mathrm{~g}^{-1}$ with the Coulombic efficiency of about $99.0 \%$, indicating excellent cycling stability and high reversibility. The slightly increased capacity in the initial 50 cycles might be due to an electrochemical activation process that creates the lithium- 
ion transportation channels in the anode materials. ${ }^{44,45}$ It was quite astonishing to achieve the remarkable high capacity, excellent stability, and rate capability for the pristine $\left\{\mathbf{M o}_{72} \mathbf{V}_{30}\right\}$. The reversible capacity of $\left\{\mathbf{M o}_{72} \mathbf{V}_{30}\right\} \quad(\sim 1300$ $\mathrm{mA} \mathrm{h} \mathrm{g}^{-1}$ at $\left.100 \mathrm{~mA} \mathrm{~g}^{-1}\right)$ is approximately three times higher than that of the commercial graphite anode $\left(372 \mathrm{~mA} \mathrm{~h} \mathrm{~g}^{-1}\right)$. Compared with other POM anodes, ${ }^{22-33}$ the $\left\{\mathbf{M o}_{72} \mathbf{V}_{30}\right\}$ anode conducts much higher capacity and cycling stability, indicating that it is a promising anode material for LIBs.

3.3. Charge-Storage Mechanism Studies. Owing to the excellent electrochemical performance and unique features of the $\left\{\mathbf{M o}_{72} \mathbf{V}_{30}\right\}$ anode, we conducted several in situ and ex situ techniques to investigate the charge-storage mechanism. Lan et al. utilized ex situ XPS measurement to investigate the oxidation state of Mo and V in EMI-Mo ${ }_{72} \mathrm{~V}_{30} @ \mathrm{rGO}$ before and after being lithiated to $0.01 \mathrm{~V}$, and they found out that the Mo can be reduced from $\mathrm{Mo}^{6+}$ to $\mathrm{Mo}^{4+}$ and $\mathrm{V}$ can be reduced from $\mathrm{V}^{5+}$ to $\mathrm{V}^{2+}$. Our ex situ XPS results in Figure S3 also indicate the valence change in Mo and $\mathrm{V}$ in $\left\{\mathbf{M o}_{72} \mathbf{V}_{30}\right\}$, where the oxidation states of Mo were partially reduced from $\mathrm{Mo}^{6+}$ to $\mathrm{Mo}^{4+} / \mathrm{Mo}^{3+}$ after being lithiated to $0.01 \mathrm{~V}$ versus $\mathrm{Li} / \mathrm{Li}^{+}$, and the oxidation states of $\mathrm{V}$ were partially reduced from $\mathrm{V}^{5+} / \mathrm{V}^{4+}$ to $\mathrm{V}^{3+} / \mathrm{V}^{2+}$ after being lithiated to $0.01 \mathrm{~V}$ versus $\mathrm{Li} / \mathrm{Li}^{+}$. After being delithiated to $3 \mathrm{~V}$ versus $\mathrm{Li} / \mathrm{Li}^{+}$, the oxidation states of $\mathrm{Mo}$ and $\mathrm{V}$ returned back to the initial states $\left(\mathrm{Mo}^{6+}\right.$ and $\left.\mathrm{V}^{5+/ 4+}\right)$. However, the ex situ measurement cannot accurately determine the valence number change because it is too sensitive to the ambient air. Therefore, in operando XANES is necessary to determine the exact redox reactions during cycling.

To investigate what oxidation states are involved and how many electrons are transferred during the lithiation/delithiation processes exactly, the in operando synchrotron Mo and $\mathrm{V}$ K-edge XANES studies of $\left\{\mathbf{M o}_{72} \mathbf{V}_{30}\right\}$ were employed. Figure 4a displays the Mo K-edge XANES spectra of the $\left\{\mathbf{M o}_{72} \mathbf{V}_{30}\right\}$ anode during the first lithiation, the first delithiation, and the second lithiation processes at $100 \mathrm{~mA} \mathrm{~g}^{-1}$; it reveals a systematic and reversible energy shift. In order to figure out the valence change in $\mathrm{Mo}$ ions, $\mathrm{MoO}_{3}, \mathrm{MoO}_{2}$ powders, and $\mathrm{Mo}$ metal foil were used as references (each of them was calibrated by Mo metal foil), as shown in Figure S4. The XANES spectra for the initial two cycles are shown in Figure $4 \mathrm{~b}$ with the potentials at OCV (ca. $2.86 \mathrm{~V}$ ), the first full lithiation at $0.01 \mathrm{~V}$ versus $\mathrm{Li} / \mathrm{Li}^{+}(1 \mathrm{~L})$, the first full delithiation at $3 \mathrm{~V}$ versus $\mathrm{Li} /$ $\mathrm{Li}^{+}(1 \mathrm{D})$, and the second lithiation at $0.01 \mathrm{~V}$ versus $\mathrm{Li} / \mathrm{Li}^{+}$ (2L). Owing to the low-edge jump, the self-absorption phenomenon is not evident, as observed in Figure $4 \mathrm{~b}$. A low-energy shift of the absorption curves during the lithiation process can be observed, and the curve shifts back to the initial position after the delithiation process. The energy edge of OCV is close to that of $\mathrm{MoO}_{3}$, indicating that the valence of $\mathrm{Mo}$ at $\mathrm{OCV}$ is close to $\mathrm{Mo}^{6+}$. When the electrode was lithiated to $0.01 \mathrm{~V}$ versus $\mathrm{Li} / \mathrm{Li}^{+}$, the energy edge moved to a lower energy than the position of $\mathrm{MoO}_{2}$. It indicates that the valence of Mo is lower than that of $\mathrm{Mo}^{4+}$. The energy edge of $1 \mathrm{D}$ shifts back to the position of OCV, indicating that the reversible reaction occurred during the first cycle. The XANES absorption edge energy is proportional to the oxidation state of Mo. Through linear combination fitting, the averaged valence of the Mo ions in $\left\{\mathbf{M o}_{72} \mathbf{V}_{30}\right\}$ at different potentials can be determined, as shown in Figure $4 \mathrm{c}$. Similar to the XPS result, the average valence of the $\left\{\mathbf{M o}_{72} \mathbf{V}_{30}\right\}$ electrode at OCV is ca. $\mathrm{Mo}^{6+}$. After the first full lithiation process, the average valence of Mo decreases to ca. $\mathrm{Mo}^{1+}$. This indicates that during the lithiation process, the Mo ion in one $\left\{\mathbf{M o}_{72} \mathbf{V}_{30}\right\}$ molecule can transfer ca. 360 additional electrons (assumed that all the $\mathrm{Mo}^{6+}$ ions in $\left\{\mathbf{M o}_{72} \mathbf{V}_{30}\right\}$ are reduced to $\left.\mathrm{Mo}^{1+}\right)$. The average valence of Mo in the following delithiation process increases from $\mathrm{Mo}^{1+}$ to $\mathrm{Mo}^{6+}$. In the second lithiation process, the average valence of $\mathrm{Mo}$ decreases from $\mathrm{Mo}^{6+}$ to $\mathrm{Mo}^{1+}$ again, revealing that it is a highly reversible process. The in operando synchrotron V K-edge XANES studies of the $\left\{\mathbf{M o}_{72} \mathbf{V}_{30}\right\}$ anode during the first cycle at $100 \mathrm{~mA} \mathrm{~g}^{-1}$ were also conducted, as displayed in Figure 4d. Owing to the low vanadium content in $\left\{\mathbf{M o}_{72} \mathbf{V}_{30}\right\}$ and the low absorption edge energy of vanadium, the curves are not smooth but enough for distinguishing the energy shift. The pre-edge peaks can be detected clearly when the $\mathrm{V}$ ions were at the high oxidation state; while the pre-edge peaks became obscure after being lithiated to the low potential, which means that the valence of $\mathrm{V}$ decreased. However, the pre-edge peak became clear again after being delithiated to $3 \mathrm{~V}$ versus $\mathrm{Li} / \mathrm{Li}^{+}$, revealing a reversible energy shift after full delithiation. The V K-edge XANES spectra of $\left\{\mathbf{M o}_{72} \mathbf{V}_{30}\right\}$ at $1 \mathrm{~L}$ and $1 \mathrm{D}$ states were compared with those of the references $\left(\mathrm{V}_{2} \mathrm{O}_{5}, \mathrm{VO}_{2}, \mathrm{~V}_{2} \mathrm{O}_{3}\right.$ powders, and $\mathrm{V}$ metal foil), as shown in Figure 4e. The energy edge of OCV is close to that of $\mathrm{V}_{2} \mathrm{O}_{5}$, showing that the valence of $\mathrm{V}$ at $\mathrm{OCV}$ is close to that of $\mathrm{V}^{5+}$. When the electrode was lithiated to $0.01 \mathrm{~V}$ versus $\mathrm{Li} / \mathrm{Li}^{+}$, the energy edge moves to a lower energy which is between $\mathrm{V}$ metal foil and $\mathrm{V}_{2} \mathrm{O}_{3}$, indicating that the average valence of vanadium is lower than $\mathrm{V}^{3+}$. Then, the energy edge shifts to higher energy close to $\mathrm{V}_{2} \mathrm{O}_{5}$ at the full delithiation state indicating that $\mathrm{V}$ is oxidized to higher valence $\left(\mathrm{ca} . \mathrm{V}^{5+}\right)$. Through linear combination fitting, the averaged valence of the vanadium ion in $\left\{\mathbf{M o}_{72} \mathbf{V}_{30}\right\}$ at different potentials can be determined, as shown in Figure $4 \mathrm{f}$. Similar to the XPS result, the average valence of the $\left\{\mathbf{M o}_{72} \mathbf{V}_{30}\right\}$ electrode at OCV is ca. $\mathrm{V}^{4.7+}$. The oxidation state of $\mathrm{V}$ in the $\left\{\mathbf{M o}_{\mathbf{7 2}} \mathbf{V}_{30}\right\}$ electrode before cycling was partially oxidized from $\mathrm{V}^{4+}$ to $\mathrm{V}^{5+}$, which may be attributed to the oxidation reaction of $\left\{\mathbf{M o}_{72} \mathbf{V}_{30}\right\}$ during the electrode preparation process. During the first lithiation process, the average valence of vanadium decreased to ca. $\mathrm{V}^{1+}$. The valence of $\mathrm{V}$ oxidized to $\mathrm{V}^{4.7+}$ after the first full delithiation process. This result indicates that the $\mathrm{V}$ ion in one $\left\{\mathbf{M o}_{72} \mathbf{V}_{30}\right\}$ molecule can transfer ca. 120 additional electrons (assumed that all the $\mathrm{V}^{5+}$ ions in $\left\{\mathbf{M o}_{72} \mathbf{V}_{30}\right\}$ are reduced to $\left.\mathrm{V}^{1+}\right)$. Therefore, it demonstrates that the lithiation/delithiation processes of the $\left\{\mathbf{M o}_{72} \mathbf{V}_{30}\right\}$ anode are accompanied with several reversible redox reactions from both Mo and V ions in the $\left\{\mathbf{M o}_{72} \mathbf{V}_{30}\right\}$ molecule, which leads to high capacity and cycling stability, as shown in Figure 3d.

According to the result obtained from the in operando synchrotron XANES, we proposed the following redox reactions of the $\left\{\mathbf{M o}_{72} \mathbf{V}_{30}\right\}$ molecule

$$
\begin{gathered}
\mathrm{Na}_{2} \mathrm{~K}_{23}\left\{\mathrm{Mo}_{72}^{\mathrm{VI}} \mathrm{V}_{30}^{\mathrm{V}}\right\}+480 \mathrm{Li}^{+}+480 \mathrm{e}^{-} \\
\leftrightarrow \mathrm{Li}_{480} \mathrm{Na}_{2} \mathrm{~K}_{23}\left\{\mathrm{Mo}_{72}^{\mathrm{I}} \mathrm{V}_{30}^{\mathrm{I}}\right\}
\end{gathered}
$$

Based on this equation, ca. 480 electrons transfer in one $\left\{\mathbf{M o}_{72} \mathbf{V}_{30}\right\}$ molecule, and a theoretical capacity of $754 \mathrm{~mA} \mathrm{~h}$ $\mathrm{g}^{-1}$ can be estimated. However, the experimental values exceed the expected value. This is similar to the results reported by Awaga et al. with $\mathrm{TBA}_{3}\left[\mathrm{PMo}_{12} \mathrm{O}_{40}\right] /$ RGO electrodes. ${ }^{46}$ Dunn et al. proposed a theory that the excess capacity is due to the interfacial lithium-storage mechanism, that is, the capacitive behavior, which consists of the non-Faradaic capacity, electrical double-layer capacitance, and pseudocapacitance. ${ }^{47}$ Therefore, 

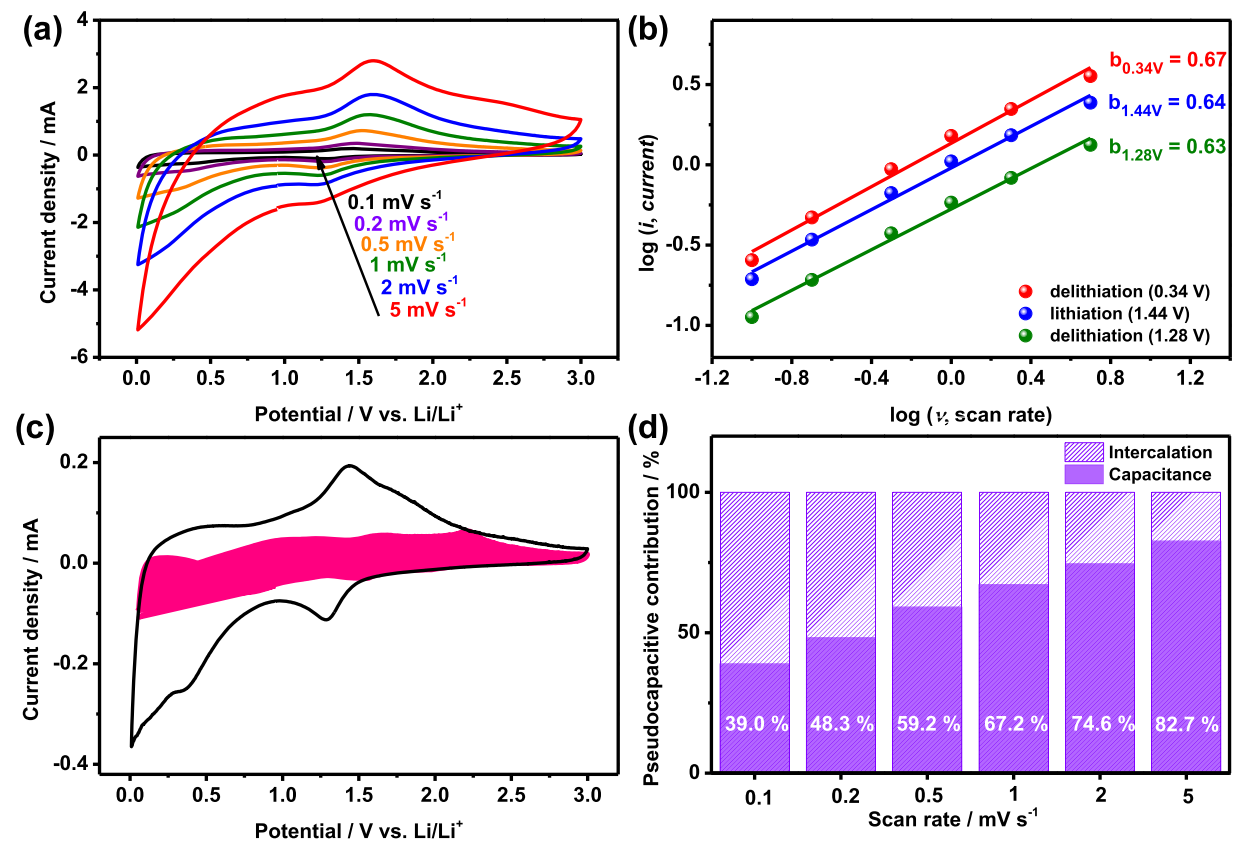

Figure 5. (a) CV curves of $\left\{\mathrm{Mo}_{72} \mathrm{~V}_{30}\right\}$ at different scan rates from 0.1 to $5 \mathrm{mV} \mathrm{s}^{-1}$. (b) $b$-value determination of $0.34,1.28$, and $1.58 \mathrm{~V}$ cathodic current and 1.44 and $2.8 \mathrm{~V}$ anodic current. (c) Estimation of pseudocapacitive-controlled charge-storage contribution at a $0.1 \mathrm{mV} \mathrm{s}{ }^{-1}$ scan rate. (d) Comparison of the pseudocapacitive-controlled ratio for different scan rates $0.1,0.2,0.5,1.0,2.0$, and $5.0 \mathrm{mV} \mathrm{s}^{-1}$.

we also simulated the capacitive behavior using Dunn's method. Figure 5a displays the $\mathrm{CV}$ curves measured at different scan rates ranging between 0.1 and $5 \mathrm{mV} \mathrm{s}^{-1}$. The capacities calculated from $\mathrm{CV}$ curves at scan rates ranging between 0.1 and $5 \mathrm{mV} \mathrm{s}^{-1}$ are similar to the capacities obtained from GCD with the current densities between 100 and 2000 $\mathrm{mA} \mathrm{g}^{-1}$. Therefore, we analyzed the surface-limited capacitive and diffusion-controlled process via $\mathrm{CV}$ curves between 0.1 and $5 \mathrm{mV} \mathrm{s}^{-1}$. The $\mathrm{CV}$ peak current $(i)$ obeys the power-law relationship with scan rate $(v): i=a v^{b}$, where $a$ and $b$ are adjustable parameters. ${ }^{48}$ When $b=1$, the capacitive current is proportional to the scan rate $(v)$, indicating that the reactions are surface-limited processes. When $b=0.5$, it means that the reactions are the diffusion-controlled process. ${ }^{26}$ The adjustable parameter $b$ can be measured from the slope of the linear plot, as shown in Figure 5b. It is worth noting that the $b$ value at $0.34,1.28$, and $1.44 \mathrm{~V}$ versus $\mathrm{Li} / \mathrm{Li}^{+}$was calculated to be 0.67 , 0.63 , and 0.64 , respectively. This indicates a combination of diffusion-controlled and surface-limited storage processes. A closer examination of voltammetric scan rate dependence can help distinguish quantitatively the capacitive contribution to the current response. The current response from the $\mathrm{CV}$ curves at a fixed potential can be separated by two mechanisms: surface-limited capacitive effects (Faradaic pseudocapacitance and/or non-Faradaic double-layer effect) and diffusioncontrolled process 49

$$
i(V)=k_{1} v+k_{2} v^{0.5}
$$

where $\mathrm{k}_{1} v$ and $\mathrm{k}_{2} v^{0.5}$ correspond to the current contribution from surface-limited capacitive effects and diffusion-controlled process, respectively. Therefore, it is possible to determine the current response resulted from surface-limited capacitive and diffusion-controlled process by determining $k_{1}$ and $k_{2}$. In Figure $5 c$, the voltage profile of the capacitive current response is shown by the shaded area in comparison with the total measured current on a typical CV for $\left\{\mathbf{M o}_{72} \mathbf{V}_{30}\right\}$ at a scan rate of $0.1 \mathrm{mV} \mathrm{s}^{-1}$. The result shows that the capacity of the capacitive-controlled process is approximately $39.0 \%$, which contributed the excess capacity beyond the theoretical capacity estimated by eq 2 . Furthermore, with the increase in the scan rate, the effect of capacitive-controlled process enlarges, as shown in Figure $5 \mathrm{~d}$. At a scan rate of $5 \mathrm{mV} \mathrm{s}^{-1}$, the role of capacitive contribution further increased to $82.7 \%$. It demonstrates that surface-limited capacitive behavior dominates the charge-storage process, especially at high scan rates which leads to the excellent rate capability. In brief, the observed high capacity in experiments can be well-explained by the contribution from both the multiple valence change in $\mathrm{Mo} / \mathrm{V}$ and the capacitive contribution.

$E x$ situ XRD measurements were conducted to observe the change in the crystal structure of the $\left\{\mathbf{M o}_{72} \mathbf{V}_{30}\right\}$ electrode during the lithiation/delithiation process, as shown in Figure 6. The cell was first lithiated from OCV to $0.01 \mathrm{~V}$ versus $\mathrm{Li} / \mathrm{Li}^{+}$ and then delithiated to $3 \mathrm{~V}$ versus $\mathrm{Li} / \mathrm{Li}^{+}$at a current density of $100 \mathrm{~mA} \mathrm{~g}^{-1}$. After cycling, the two broad peaks at around 11.4

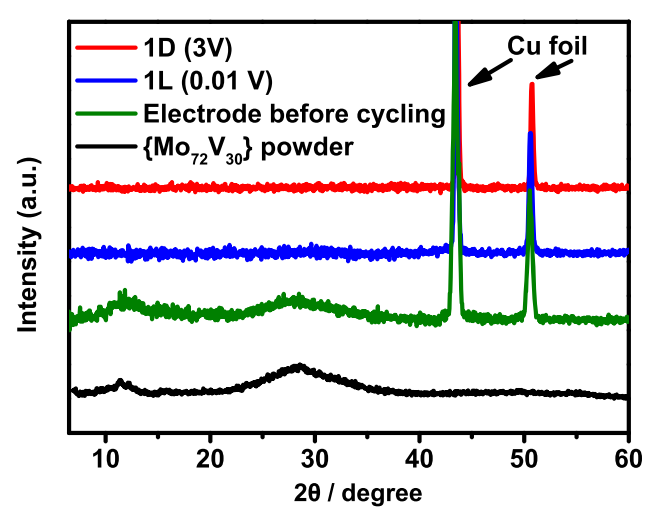

Figure 6. Ex situ XRD spectra of $\left\{\mathbf{M o}_{72} \mathbf{V}_{30}\right\}$ electrodes before cycling, after lithiated to $0.01 \mathrm{~V}$ vs $\mathrm{Li} / \mathrm{Li}^{+}$, and delithiated to $3 \mathrm{~V}$ vs $\mathrm{Li} / \mathrm{Li}^{+}$. 
(a)

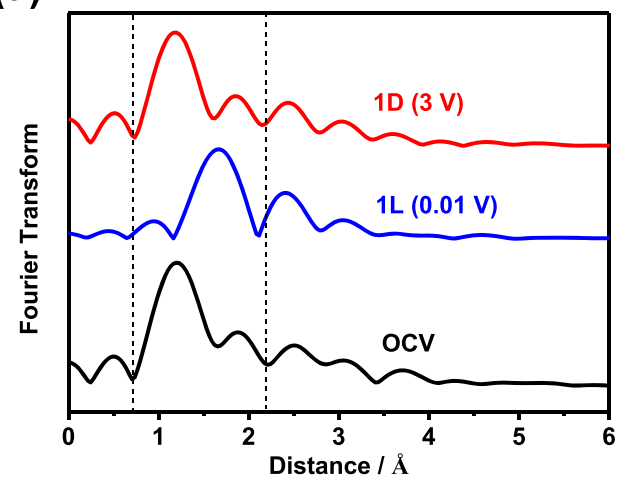

(b)

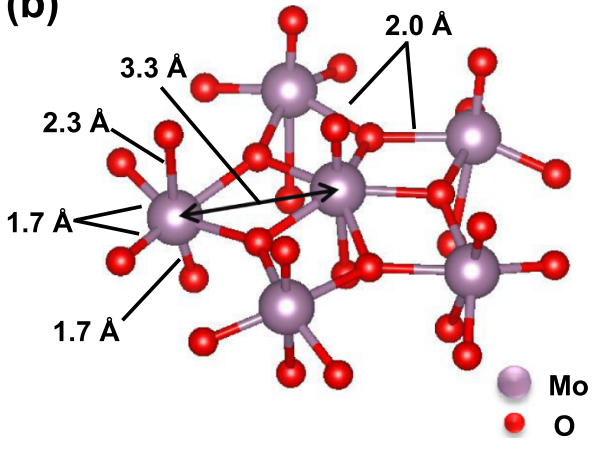

Figure 7. (a) Experimental Mo K-edge EXAFS spectra of the $\left\{\mathbf{M o}_{\mathbf{7 2}} \mathbf{V}_{30}\right\}$ electrode at OCV, the first full lithiation, and the first full delithiation. (b) Local structure of $\left[\mathrm{Mo}_{6} \mathrm{O}_{21}\right]^{6-}$.

and $28.6^{\circ}$ disappeared, and there was no significant reflection or shift, indicating that the crystal structure of the $\left\{\mathbf{M o}_{72} \mathbf{V}_{30}\right\}$ electrode was more amorphous and remained in the amorphous state through the lithiation/delithiation processes. It demonstrates that the lithiation/delithiation reactions in the amorphous $\left\{\mathbf{M o}_{72} \mathbf{V}_{30}\right\}$ electrode are independent from its crystal structure. This statement is consistent with the other POM cathode, $\mathrm{K}_{7}\left[\mathrm{NiV}_{13} \mathrm{O}_{38}\right]$, reported by $\mathrm{Ni}$ et al. ${ }^{36}$

According to the ex situ XRD results, the crystal structure of the $\left\{\mathbf{M o}_{72} \mathbf{V}_{30}\right\}$ electrode lacked a long-range order after the lithiation/delithiation process. The EXAFS analysis, which is a useful tool for investigating short-range-order structures, was utilized to gain insight into the molecular structure of $\left\{\mathbf{M o}_{72} \mathbf{V}_{30}\right\}$ before and after cycling. The ex situ Mo K-edge EXAFS results of the $\left\{\mathbf{M o}_{72} \mathbf{V}_{30}\right\}$ electrodes at OCV, $1 \mathrm{~L}$, and 1D were recorded under the transmission mode. The $k^{3} \chi(k)$ functions obtained from Mo absorption spectra are shown in Figure S5. Figure 7a shows the corresponding Fourier transform (FT) spectra (the $\mathrm{k}$ range is approximately 3.0$10.0 \AA^{-1}$ ), which provide a radial distribution of the nearest neighbor atoms around the Mo atoms. The complex $\left\{\mathbf{M o}_{72} \mathbf{V}_{30}\right\}$ molecule was simplified to a $\left[\mathrm{Mo}_{6} \mathrm{O}_{21}\right]^{6-}$ polyoxomolybdate unit to analyze the local structure, as shown in Figure $7 \mathrm{~b}$. The structural parameters obtained by fitting the experimental EXAFS data are summarized in Table S2, and the fitting curves are shown in Figure S6. In Figure 7a, two main peaks are observed at 1.2 and $1.9 \AA$ in the $\left\{\mathbf{M o}_{72} \mathbf{V}_{30}\right\}$ electrode at OCV. The peaks are contributed by the $\mathrm{Mo}-\mathrm{O}$ bonds. These two distances are denoted in the molecular structure of $\left[\mathrm{Mo}_{6} \mathrm{O}_{21}\right]^{6-}$ shown in Figure $7 \mathrm{~b}$. The distance in the Fourier transformation is approximately $0.5 \AA$, which is shorter than that in the molecular structure owing to the phase factor. ${ }^{50}$ According to Figure $7 \mathrm{~b}$, there are three $\mathrm{Mo}-\mathrm{O}$ bonds with a distance of $1.7 \AA$, two $\mathrm{Mo}-\mathrm{O}$ bonds with a distance of 2 $\AA$, and one $\mathrm{Mo}-\mathrm{O}$ bond with a distance of $2.4 \AA$. Therefore, the coordination numbers at OCV shown in Table $\mathrm{S} 2$ are as expected. After the first lithiation process, the intensities of the peaks at 1.2 and $1.9 \AA$ decreased and increased, respectively. This implies that the coordination numbers of the first and second Mo-O bonds decreased and increased, respectively, as shown in Table S2. This result reveals that the lithium ions formed ionic bonds with the oxygen atoms. Thus, the valence of Mo decreased, which caused the Mo-O bond length to increase during the lithiation process. After the first delithiation process, the FT-EXAFS curve and the coordination number returned to the original state (the same as those at OCV). This demonstrates that the molecular structure of $\left\{\mathbf{M o}_{72} \mathbf{V}_{30}\right\}$ remains stable and the change in the $\mathrm{Mo}-\mathrm{O}$ bond length is reversible during the lithiation/delithiation process.

The in operando Raman spectra of the $\left\{\mathbf{M o}_{72} \mathbf{V}_{30}\right\}$ electrode during the first lithiation process are shown in Figure 8. The
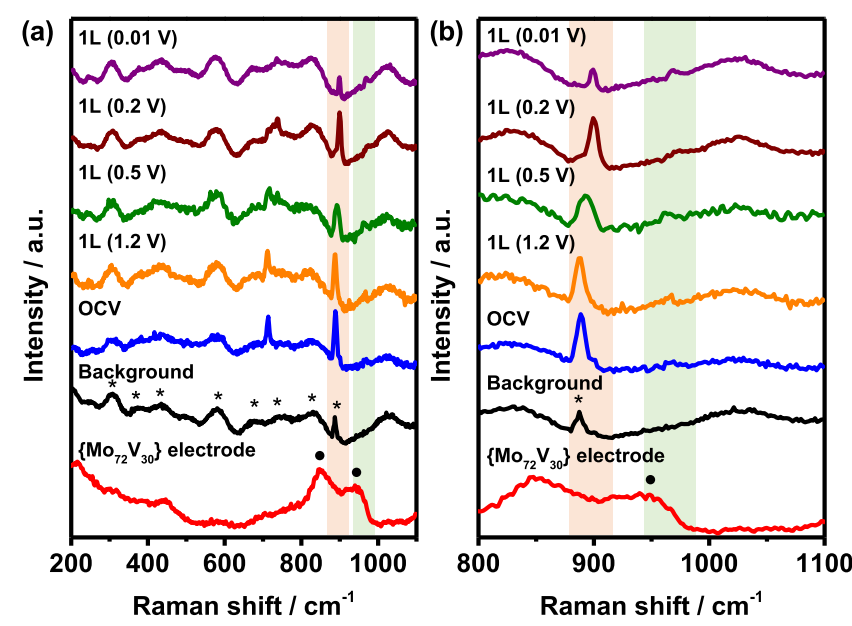

Figure 8. (a) In operando Raman spectra of the $\left\{\mathbf{M o}_{72} \mathbf{V}_{30}\right\}$ electrode during the first lithiation process (* electrolyte, $\bullet\left\{\mathbf{M o}_{72} \mathbf{V}_{30}\right\}$ ). (b) Magnified view of (a).

background profile was recorded with an active-material free electrode, which was coated with carbon black (Super P) and a sodium CMC binder in the electrolyte. In Figure $8 \mathrm{a}$, the characteristic peaks contributed by the carbon black, binder, and electrolyte are indicated by stars $(*)$. The characteristic peaks of $\left\{\mathbf{M o}_{72} \mathbf{V}_{30}\right\}$ located at approximately 870 and 960 $\mathrm{cm}^{-1}$ are indicated by circles $(\bullet)$. The Raman band of free EC $\left(891 \mathrm{~cm}^{-1}\right)$ can be observed at the background and OCV electrodes. During the first lithiation process, a notable peak shifts from 891 to $902 \mathrm{~cm}^{-1}$ in the voltage range of $0.5-0.01 \mathrm{~V}$ (as shown in the orange region in Figure 8a), which corresponds to the process of lithium-ion-coordinated EC, indicating the formation of the SEI layer on the electrode surface. ${ }^{51}$ The characteristic peak of $\left\{\mathbf{M o}_{72} \mathbf{V}_{30}\right\}$ at $870 \mathrm{~cm}^{-1}$ is covered by the EC signal and it is difficult to distinguish. Nevertheless, as shown in the green region in Figure $8 \mathrm{~b}$, the characteristic peak of $\left\{\mathbf{M o}_{72} \mathbf{V}_{30}\right\}$ at $960 \mathrm{~cm}^{-1}$ can still be observed on the electrodes, even after the first lithiation process. This indicates that the molecular structure of 


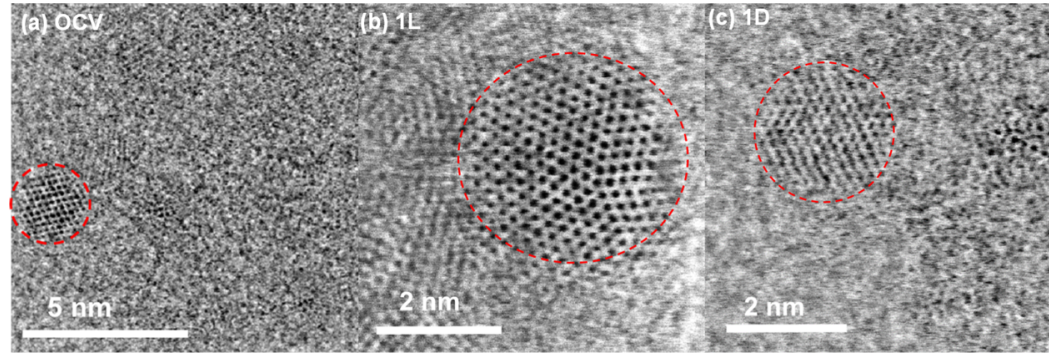

Figure 9. HRTEM image of the (a) $\left\{\mathbf{M o}_{72} \mathbf{V}_{30}\right\}$ electrode before cycling, (b) $\left\{\mathbf{M o}_{72} \mathbf{V}_{30}\right\}$ electrode at the first full lithiation state, (c) $\left\{\mathbf{M o} \mathbf{o}_{72} \mathbf{V}_{30}\right\}$ electrode at the first full delithiation state.

(a)

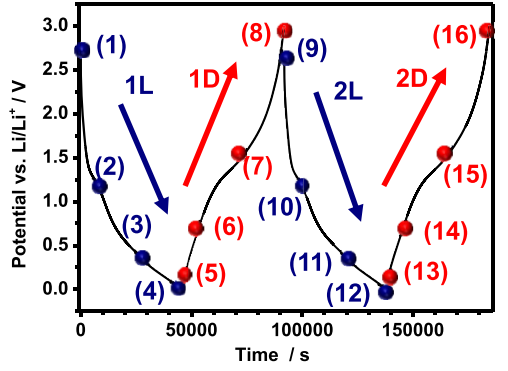

(b)

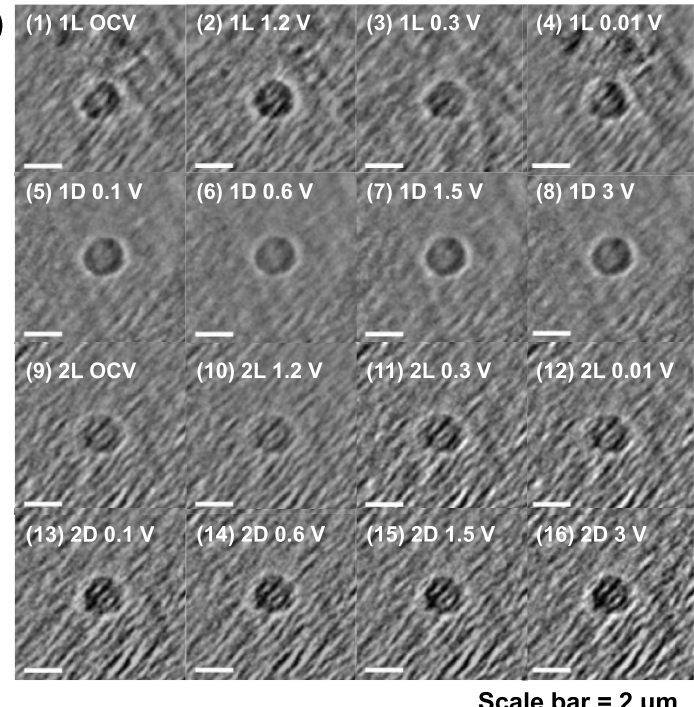

Scale bar $=2 \mu \mathrm{m}$

Figure 10. (a) GCD curves of the $\left\{\mathbf{M o}_{72} \mathbf{V}_{30}\right\}$ anode at a current density of $100 \mathrm{~mA} \mathrm{~g}^{-1}$ and (b) corresponding TXM images during cycling.

$\left\{\mathbf{M o}_{72} \mathbf{V}_{30}\right\}$ remains intact after the lithiation process. This result is consistent with the abovementioned ex situ EXAFS analysis.

The morphologies and microstructures of $\left\{\mathbf{M o}_{72} \mathbf{V}_{30}\right\}$ were investigated by ex situ TEM to explore the molecular structural transformation of $\left\{\mathbf{M o}_{72} \mathbf{V}_{30}\right\}$ during the lithiation/delithiation process. Figure 9a shows the HRTEM image of $\left\{\mathbf{M o}_{72} \mathbf{V}_{30}\right\}$ at OCV. The diameter of a single spherical $\left\{\mathbf{M o}_{72} \mathbf{V}_{30}\right\}$ molecule is approximately $2.2 \mathrm{~nm}$. The random arrangement and open framework of $\left\{\mathbf{M o}_{72} \mathbf{V}_{30}\right\}$ molecules can facilitate electron/ion transport; thus, $\left\{\mathbf{M o}_{\mathbf{7 2}} \mathbf{V}_{\mathbf{3 0}}\right\}$ molecules are beneficial for lithium-ion storage. Figure $9 \mathrm{~b}$ shows the HRTEM image of the $\left\{\mathbf{M o}_{72} \mathbf{V}_{30}\right\}$ electrode after the first full lithiation process. The diameter of $\left\{\mathbf{M o}_{72} \mathbf{V}_{30}\right\}$ molecules $(\sim 2.5 \mathrm{~nm})$ is slightly larger than that at OCV. However, the volumetric expansion caused by the lithium-ion intercalation is relatively small as compared with other metal oxide anodes (e.g., $\mathrm{SnO}_{2}$ : $\sim 300 \%{ }^{52} \mathrm{MoO}_{3}: 104 \%{ }^{53}$ and $\left.\mathrm{V}_{2} \mathrm{O}_{3}: 190 \%{ }^{54}\right)$. Figure 9c displays the HRTEM of the $\left\{\mathbf{M o}_{72} \mathbf{V}_{30}\right\}$ electrode after the first full delithiation process. The diameter of $\left\{\mathbf{M o}_{72} \mathbf{V}_{30}\right\}$ molecules decreases to the original size. This demonstrates that the lithium ions are inserted into the hollow-structured $\left\{\mathbf{M o}_{72} \mathbf{V}_{30}\right\}$ molecule but do not undergo extreme volume expansion during the lithiation process.

To gain additional insights into the volume changes of the microscale particles that occur in the $\left\{\mathbf{M o}_{72} \mathbf{V}_{30}\right\}$ anode, we conducted in operando synchrotron TXM measurement. Figure 10a shows the first and second GCD curves during TXM measurement, and Figure $10 \mathrm{~b}$ displays the corresponding TXM images of a single microsized $\left\{\mathbf{M o}_{72} \mathbf{V}_{30}\right\}$ particle (but not a single molecule) in the anode at different lithiation/ delithiation states. These TXM images display good contrast between the $\left\{\mathbf{M o}_{72} \mathbf{V}_{30}\right\}$ particle and the electrode/electrolyte interface because of their different atomic numbers. During the two completed cycles of lithiation/delithiation processes, the volume of the $\left\{\mathbf{M o}_{72} \mathbf{V}_{30}\right\}$ particle did not change significantly, which can be attributed to its amorphous characteristics. The lack of the long-range order in the $\left\{\mathbf{M o}_{72} \mathbf{V}_{30}\right\}$ particle can be observed in the XRD patterns. This kind of amorphous structure provides a high tolerance to the small volume expansion of each single $\left\{\mathbf{M o}_{72} \mathbf{V}_{30}\right\}$ molecule. These results provide the strong evidence for the excellent cycling stability of the $\left\{\mathbf{M o}_{72} \mathbf{V}_{30}\right\}$ anode, as shown in Figure $3 \mathrm{~d}$.

The lithium-ion diffusion coefficient $\left(D_{\mathrm{Li}^{+}}\right)$was estimated using the PITT method. This technique characterizes a battery by small voltage steps, and the change in current is recorded. The Li-ion diffusion coefficient $\left(D_{\mathrm{Li}^{+}}\right)$can be derived by

$$
D_{\mathrm{Li}^{+}}=\frac{\mathrm{d} \ln (I)}{\mathrm{d} t} \cdot \frac{4 L^{2}}{\pi^{2}}
$$

where $I$ is the current, $t$ is the step time, $L$ is the diffusion distance which can be calculated by $L=V_{\mathrm{M}} n_{\mathrm{B}} / S, V_{\mathrm{M}}$ is the molar volume of the electrode materials, $n_{\mathrm{B}}$ is the number of moles of the electrode materials in the sample, and $S$ is the cross-sectional area of the electrode sample and electrolyte. This equation is based on Fick's second law with the 
(a)

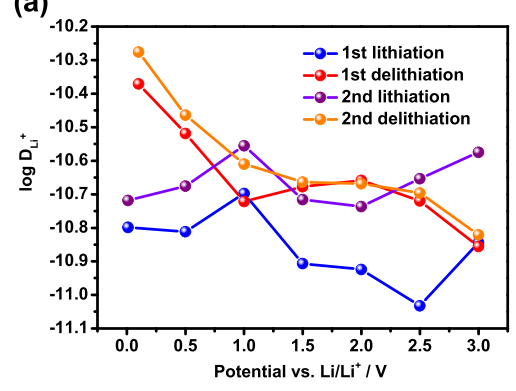

(b)

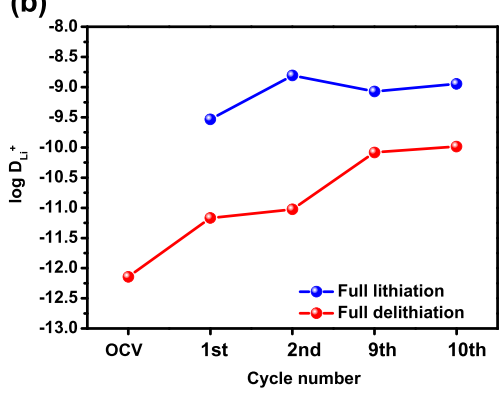

(c)

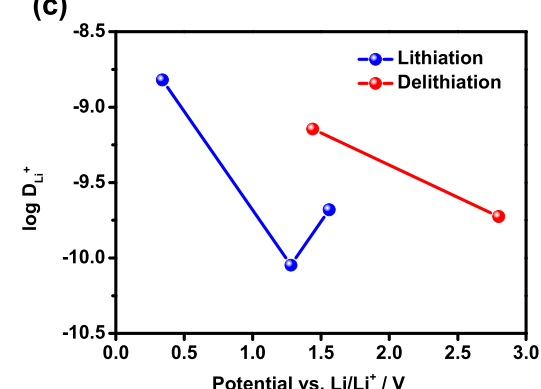

Figure 11. (a) Lithium-ion diffusion coefficient of $\left\{\mathbf{M o}_{72} \mathbf{V}_{30}\right\}$ during the lithiation and delithiation process measured using the PITT method. (b) Lithium-ion diffusion coefficient of $\left\{\mathbf{M o}_{72} \mathbf{V}_{30}\right\}$ at the fully lithiated/delithiated states calculated by the EIS measurements. (c) Lithium-ion diffusion coefficient of $\left\{\mathbf{M o}_{72} \mathbf{V}_{30}\right\}$ during the lithiation/delithiation processes calculated using the Randles-Sevcik equation.

hypothesis of one-dimensional transport and it was derived based on the long-time approximation $\left(t \gg L^{2} / D_{\mathrm{A}}^{\text {chem }}\right){ }^{55}$ Figure S7a shows the $I-t$ plots during the first lithiation process. It indicates that the current is stable after the holding time of $3600 \mathrm{~s}$. Figure $S 7 \mathrm{~b}$ shows the $\ln (I)-t$ plots and the fitting line from 1000 to $3600 \mathrm{~s}\left(t \gg L^{2} / D_{\mathrm{A}}^{\text {chem }}\right)$. The slope of the fitting line represents $\mathrm{d} \ln (I) / \mathrm{d} t$ in eq 3 . Figure 11a shows the $D_{\mathrm{Li}^{+}}$during the first and second lithiation and delithiation processes based on eq 3 , and the value of $D_{\mathrm{Li}^{+}}$ranged between $10^{-10}$ and $10^{-11} \mathrm{~cm}^{2} \mathrm{~s}^{-1}$. Table 1 compares the $D_{\mathrm{Li}^{+}}$of LIB

Table 1. $\mathrm{Li}^{+}$Diffusion Coefficient of LIB Negative Electrode Materials Measured by PITT

\begin{tabular}{|c|c|c|}
\hline electrode & $\begin{array}{l}\mathrm{Li}^{+} \text {diffusion Coefficient } \\
\left(\mathrm{cm}^{2} \mathrm{~s}^{-1}\right)\end{array}$ & refs \\
\hline $\mathrm{Li}_{4} \mathrm{Ti}_{5} \mathrm{O}_{12}$ & $3 \times 10^{-12}$ & 56,57 \\
\hline $\mathrm{Li}_{4} \mathrm{Ti}_{5} \mathrm{O}_{12}$ thin film & $10^{-10}-10^{-11}$ & 58 \\
\hline $\mathrm{TiO}_{2}$ & $9.91 \times 10^{-14}$ & 59 \\
\hline $\mathrm{TiO}_{2} @ \mathrm{C}$ & $3.87 \times 10^{-13}$ & 59 \\
\hline $\begin{array}{l}\alpha \text {-Fe } \mathrm{O}_{3} / \text { single-walled carbon } \\
\text { nanotube hybrid films }\end{array}$ & $4 \times 10^{-12}$ & 60 \\
\hline $\mathrm{FeNb}_{11} \mathrm{O}_{29}$ & $3.39 \times 10^{-11}-8.55 \times 10^{-12}$ & 61 \\
\hline natural graphite & $10^{-12}-10^{-15}$ & 62 \\
\hline graphite & $10^{-11}-10^{-15}$ & 62 \\
\hline spherical graphite & $10^{-9}-10^{-10}$ & 63 \\
\hline $\mathrm{Si}$ & $7.7 \times 10^{-14}$ & 64 \\
\hline nano-Si & $10^{-12}$ (by GITT) & 65 \\
\hline$\left\{\mathbf{M o}_{72} \mathbf{V}_{30}\right\}$ & $10^{-9}-10^{-10}$ & $\begin{array}{l}\text { this } \\
\text { work }\end{array}$ \\
\hline
\end{tabular}

anode materials measured by PITT in the literature. The $\left\{\mathbf{M o}_{72} \mathbf{V}_{30}\right\}$ anode has the same order of magnitude of $D_{\mathrm{Li}^{+}}$with $\mathrm{Li}_{4} \mathrm{Ti}_{5} \mathrm{O}_{12}$ and spherical graphite anodes, which exhibit excellent high rate capacity. Furthermore, the $\left\{\mathbf{M o}_{72} \mathbf{V}_{30}\right\}$ anode possesses higher $D_{\mathrm{Li}^{+}}$than other metal oxides, graphite, and silicon anodes. This high $D_{\mathrm{Li}^{+}}$of the $\left\{\mathbf{M o}_{72} \mathbf{V}_{30}\right\}$ anode can be attributed to the unique large hollow-structured molecule and the absence of the long-range order. According to the literature, the POM molecule undergoes redox reactions as a cluster and not as a continuum, and therefore, the change in the long-range crystal structure does not affect the cycling stability of POM electrodes. ${ }^{36}$ Besides, those Li ions could diffuse through the free space (vacancies or interstitial sites) and open spatial channels in the amorphous $\left\{\mathbf{M o}_{72} \mathbf{V}_{30}\right\}$ anode and thus shorten the diffusion path length and lead to high $D_{\mathrm{Li}^{+}}$ resulting in high rate capability.

The EIS measurement of the $\left\{\mathbf{M o}_{72} \mathbf{V}_{30}\right\}$ electrode was carried out during the first two cycles and the 10th and 11th cycles. The Nyquist plots of the $\left\{\mathbf{M o}_{72} \mathbf{V}_{30}\right\}$ electrode at different cycles are shown in Figure S8 and they are composed of a semicircle in the high-frequency domain and a sloping line in the low-frequency domain. The semicircle is contributed by the charge transfer resistance on the electrode/electrolyte interface, and the sloping line is the Warburg domain, which is dominated by the solid-state diffusion of lithium ions in $\left\{\mathbf{M o}_{72} \mathbf{V}_{\mathbf{3 0}}\right\}$. The Warburg coefficient, $\mathrm{A}_{\mathrm{W}}$, is defined as ${ }^{66}$

$$
A_{\mathrm{w}}=\Delta R_{\mathrm{e}} / \Delta \omega^{-1 / 2}=\Delta I_{\mathrm{m}} / \Delta \omega^{-1 / 2}
$$

where $R_{\mathrm{e}}$ and $I_{\mathrm{m}}$ are the real and imaginary components of the impedance, respectively, and $\omega$ is the frequency. The time constant for the finite diffusion process can be defined as

$$
\tau=\left[\sqrt{2} A_{\mathrm{w}} Q_{\mathrm{t}} \mathrm{d} X / \mathrm{d} E\right]^{2} A_{\mathrm{w}}
$$

where $Q_{t}$ is the total charge involved in the charge/discharge process and $\mathrm{d} X / \mathrm{d} E$ is the derivative of the intercalation isotherm with respect to $E$. In linear sweep voltammetry, $Q_{\mathrm{t}}(\mathrm{d} X / \mathrm{d} E)=I_{\mathrm{CV}} / v$, where $I_{\mathrm{CV}}$ is the voltammetric current and $v$ is the scan rate. $\tau$ can be calculated using $A_{\mathrm{w}}$ and $I_{\mathrm{CV}}$ in the range of the intercalation potentials. Finally, $D_{\mathrm{Li}^{+}}$can be determined as $D_{\mathrm{Li}^{+}}=L^{2} / \tau$, where $L$ is the diffusion distance mentioned in the PITT analysis, ${ }^{67}$ as shown in Figure $11 \mathrm{~b} . D_{\mathrm{Li}^{+}}$ is approximately $10^{-9}$ to $10^{-12} \mathrm{~cm}^{2} \mathrm{~s}^{-1}$ and it increases from the first cycle to the second cycle owing to the activation process.

$D_{\mathrm{Li}^{+}}$can also be calculated by utilizing the Randles-Sevcik equation at $25{ }^{\circ} \mathrm{C}^{68-70}$

$$
I_{\mathrm{p}}=\left(2.69 \times 10^{5}\right) n^{3 / 2} C_{0} D^{1 / 2} A v^{1 / 2}
$$

where $I_{\mathrm{p}}$ is the peak current density $(A), n$ is the electron transfer number, $C_{0}$ is the maximum $\mathrm{Li}^{+}$concentration $\left(C_{0}=\right.$ $\left.3.5 \times 10^{-3} \mathrm{~mol} \mathrm{~cm}^{-3}\right), D$ is the diffusion coefficient of the ratelimiting species $\left(\mathrm{Li}^{+}, \mathrm{cm}^{2} \mathrm{~s}^{-1}\right), A$ is the apparent surface area $\left(\mathrm{cm}^{2}\right)$, and $v$ is the scan rate $\left(\mathrm{V} \mathrm{s}^{-1}\right)$. Figure $\mathrm{S} 9$ shows the I$v^{1 / 2}$ plot and its fitting line. The slope of the fitting line can be calculated using $\left(2.69 \times 10^{5}\right)^{3 / 2} C_{0} D^{1 / 2} A$ in eq 6 . The $D_{\mathrm{Li}^{+}}$of $\left\{\mathbf{M o}_{72} \mathbf{V}_{30}\right\}$ obtained via eq 6 is shown in Figure 11c, and the value ranges from $10^{-9}$ to $10^{-10} \mathrm{~cm}^{2} \mathrm{~s}^{-1}$, which is similar to the values obtained through the PITT and EIS methods. This proves that the $D_{\mathrm{Li}^{+}}$value of the $\left\{\mathbf{M o}_{72} \mathbf{V}_{30}\right\}$ anode obtained in this study is reliable.

\section{DISCUSSION}

The $\left\{\mathbf{M o}_{72} \mathbf{V}_{30}\right\}$ anode exhibits excellent cycling stability, high rate capability, and a high lithium-ion diffusion coefficient $\left(10^{-9}\right.$ to $\left.10^{-10} \mathrm{~cm}^{2} \mathrm{~s}^{-1}\right)$. This is different from conventional 

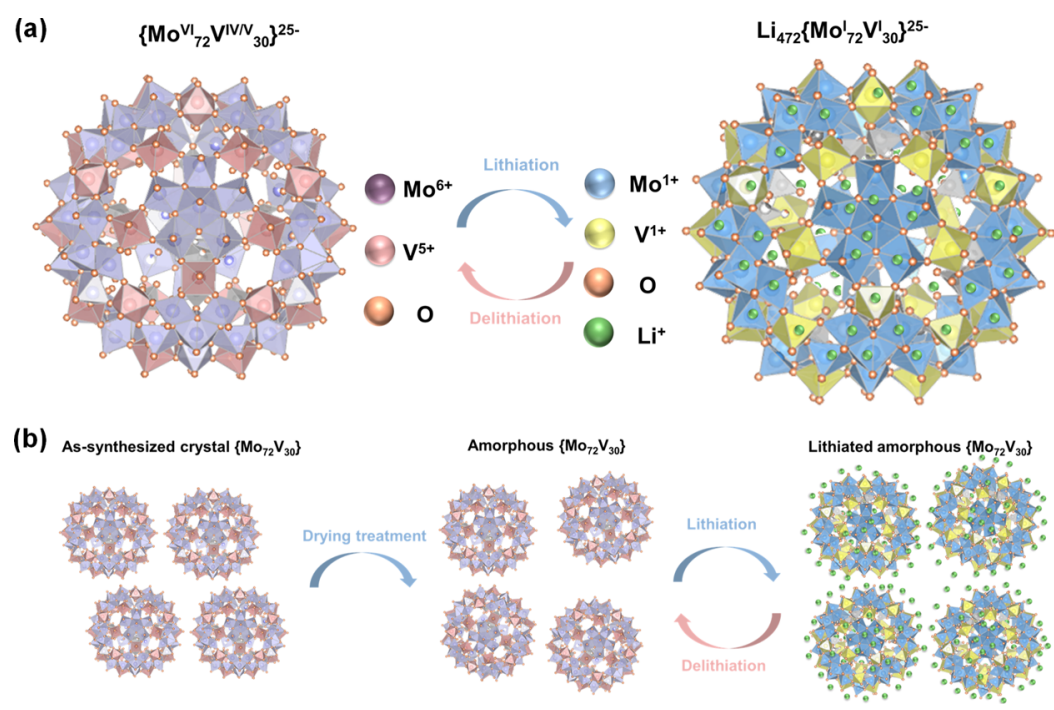

Figure 12. Schematic of the lithiation/delithiation reaction mechanism for the $\left\{\mathbf{M o}_{72} \mathbf{V}_{30}\right\}$ anode.

conversion and alloying anode materials. In addition, $\left\{\mathbf{M o}_{72} \mathbf{V}_{30}\right\}$ exhibits considerably higher capacity (1495 $\mathrm{mA} \mathrm{h}$ $\mathrm{g}^{-1}$ after 100 cycles) as compared to conventional intercalation anode materials such as graphite and LTO. Moreover, $\left\{\mathbf{M o}_{72} \mathbf{V}_{30}\right\}$ provides relatively high capacity and stability without combining with graphene, carbon nanotubes, or other high-cost ingredients as compared to other POM anodes in the literature. ${ }^{22-33}$ These outstanding performances of $\left\{\mathbf{M o}_{72} \mathbf{V}_{30}\right\}$ and the facile synthesis procedure make $\left\{\mathbf{M o}_{72} \mathbf{V}_{30}\right\}$ an extremely promising candidate for LIB anode materials. The schematic of the lithiation/delithiation reaction mechanism for the $\left\{\mathbf{M o}_{72} \mathbf{V}_{30}\right\}$ anode is displayed in Figure 12a,b. Based on the in operando XANES analyses, the $\mathrm{Mo}^{6+}$ and $\mathrm{V}^{5+} / \mathrm{V}^{4+}$ in the $\left\{\mathbf{M o}_{72} \mathbf{V}_{30}\right\}$ molecule can be reduced to $\mathrm{Mo}^{1+}$ and $\mathrm{V}^{1+}$ during the lithiation process; this results in the transfer of ca. 480 electrons per molecule. In addition to the multiple redox reactions that occur during the lithiation/delithiation processes, the hollow-ball structure provides a large surface and space for lithium-ion storage and the large voids on the molecule facilitate lithium-ion diffusion. Therefore, the $\left\{\mathbf{M o}_{72} \mathbf{V}_{30}\right\}$ anode delivers high capacity, a high lithium-ion diffusion coefficient, and high rate capability. Furthermore, the results obtained from ex situ XRD and in operando Raman spectroscopy prove that the $\left\{\mathbf{M o}_{72} \mathbf{V}_{30}\right\}$ anode remains amorphous during the lithiation/delithiation processes. However, the molecular structure of the single molecule remains, while the change in the bond length is reversible. Ex situ TEM and in operando TXM analyses reveal that the single $\left\{\mathbf{M o}_{72} \mathbf{V}_{30}\right\}$ molecule slightly expands after the lithiation process. However, the entire microsized particle does not undergo significant volume expansion. This indicates that the absence of the long-range order of the amorphous $\left\{\mathbf{M o}_{72} \mathbf{V}_{30}\right\}$ anode results in high tolerability for the volume expansion of each single molecule. Thus, the $\left\{\mathbf{M o}_{72} \mathbf{V}_{30}\right\}$ anode exhibits excellent cycling stability.

\section{CONCLUSIONS}

The Keplerate-type $\left\{\mathbf{M o}_{72} \mathbf{V}_{30}\right\}$ anode in LIBs exhibited a high reversible capacity of ca. $1300 \mathrm{~mA} \mathrm{~h} \mathrm{~g}^{-1}$ at $100 \mathrm{~mA} \mathrm{~g}^{-1}$, a high cycle stability of up to 100 cycles without fading, and a high rate capability in a current density range of $100-2000 \mathrm{~mA} \mathrm{~g}^{-1}$. These features revealed that $\left\{\mathbf{M o}_{72} \mathbf{V}_{30}\right\}$ is a promising anode candidate for high-energy and long-cycle-life LIB applications. In this work, the lithium-ion storage mechanism of the $\left\{\mathbf{M o}_{72} \mathbf{V}_{30}\right\}$ anode during the lithiation/delithiation processes was systematically investigated via in operando XANES, in operando Raman spectroscopy, in operando TXM, ex situ XRD, ex situ EXAFS, ex situ TEM, and kinetic process analyses. The multiple and reversible redox reactions $\left(\mathrm{Mo}^{6+} \leftrightarrow \mathrm{Mo}^{1+}\right.$ and $\left.\mathrm{V}^{5+} / \mathrm{V}^{4+} \leftrightarrow \mathrm{V}^{1+}\right)$ and the open hollow-ball structure of the $\left\{\mathbf{M o}_{72} \mathbf{V}_{30}\right\}$ molecule lead to a remarkably high capacity and fast lithium-ion diffusion kinetics. The $\left\{\mathbf{M o}_{72} \mathbf{V}_{30}\right\}$ anode remains amorphous during the lithiation/delithiation process, while the $\left\{\mathbf{M o}_{72} \mathbf{V}_{30}\right\}$ molecule undergoes reversible structural change (molecular size slightly increases during the lithiation process). Additionally, no significant volume expansion of the microsized $\left\{\mathbf{M o}_{72} \mathbf{V}_{30}\right\}$ particle can be observed during the lithiation process. This is due to the unique molecular structure and amorphous nature, which result in remarkable cycling stability. These experimental analyses pave the way for the further utilization of the Keplerate-type POM anodes in energy-storage applications.

\section{ASSOCIATED CONTENT}

\section{S1 Supporting Information}

The Supporting Information is available free of charge at https://pubs.acs.org/doi/10.1021/acsami.0c09344.

Crystal data; Raman, UV-vis, and XPS spectra of $\left\{\mathbf{M o}_{72} \mathbf{V}_{30}\right\}$; EXAFS model analysis; and calculations detail of $D_{\mathrm{Li}}$ (PDF)

\section{AUTHOR INFORMATION}

\section{Corresponding Author}

Han-Yi Chen - Department of Materials Science and Engineering, National Tsing Hua University, Hsinchu 30013, Taiwan; ○ orcid.org/0000-0001-8146-7101; Email: hanyi.chen@mx.nthu.edu.tw

\section{Authors}

Chia-Ching Lin - Department of Materials Science and Engineering, National Tsing Hua University, Hsinchu 30013, Taiwan 
Chi-Ting Hsu - Department of Materials Science and Engineering, National Tsing Hua University, Hsinchu 30013, Taiwan

Wenjing Liu - Department of Life Sciences and Chemistry, Jacobs University, 28759 Bremen, Germany; Key Laboratory of Flexible Electronics (KLOFE) \& Institute of Advanced Materials (IAM), Nanjing Tech University (NanjingTech), Nanjing 211816, P. R. China

Shao-Chu Huang - Department of Materials Science and Engineering, National Tsing Hua University, Hsinchu 30013, Taiwan

Ming-Hsien Lin - Department of Chemical and Materials Engineering, Chung Cheng Institute of Technology, National Defense University, Taoyuan 334, Taiwan

Ulrich Kortz - Department of Life Sciences and Chemistry, Jacobs University, 28759 Bremen, Germany; (1) orcid.org/ 0000-0002-5472-3058

Ali S. Mougharbel - Department of Life Sciences and Chemistry, Jacobs University, 28759 Bremen, Germany; (1) orcid.org/0000-0003-0108-3920

Tsan-Yao Chen - Department of Engineering and System Science, National Tsing Hua University, Hsinchu 30013, Taiwan; 이이이.org/0000-0002-6431-715X

Chih-Wei Hu - National Synchrotron Radiation Research Center, Hsinchu 30013, Taiwan

Jyh-Fu Lee - National Synchrotron Radiation Research Center, Hsinchu 30013, Taiwan

Chun-Chieh Wang - National Synchrotron Radiation Research Center, Hsinchu 30013, Taiwan

Yen-Fa Liao - National Synchrotron Radiation Research Center, Hsinchu 30013, Taiwan

Lain-Jong Li - Physical Science and Engineering Division, King Abdullah University of Science and Technology, Thuwal 23955, KSA

Linlin Li - Jiangsu Key Laboratory of Electrochemical Energy Storage Technologies, College of Materials Science and Technology, Nanjing University of Aeronautics and Astronautics, Nanjing 210016, China; 이이.org/00000001-7181-6654

Shengjie Peng - Jiangsu Key Laboratory of Electrochemical Energy Storage Technologies, College of Materials Science and Technology, Nanjing University of Aeronautics and Astronautics, Nanjing 210016, China; 이이. ord.org/00000002-6565-836X

Ulrich Stimming - Chemistry-School of Natural and Environmental Sciences, Newcastle University, Newcastle upon Tyne NE1 7RU, U.K.

Complete contact information is available at: https://pubs.acs.org/10.1021/acsami.0c09344

\section{Author Contributions}

C.-C.L. and C.-T.H. contributed equally to this manuscript.

\section{Funding}

This work was financially supported from the Young Scholar Fellowship Program by the Ministry of Science and Technology (MOST) in Taiwan (MOST109-2636-E-007007) and National Tsing Hua University (109Q2708E1). U. K. acknowledges the German Science Foundation (DFG KO2288/20-1) and Jacobs University for research support.

\section{Notes}

The authors declare no competing financial interest.

\section{ACKNOWLEDGMENTS}

The authors thank the Instrumentation Center at National Tsing Hua University for providing assistance in electron spectroscopy for chemical analysis, XRD measurement for structural analysis, and TEM for morphological and microstructural analyses. The authors also thank Dr. Chih-Wen Pao and Dr. Jeng-Lung Chen for their help on the in operando synchrotron XAS (beamline TPS 44A1) in National Synchrotron Radiation Research Center (NSRRC), Hsinchu, Taiwan.

\section{ABBREVIATIONS}

$\left\{\mathrm{M} \mathrm{O}_{72} \mathrm{~V}_{30}\right\}, \quad \mathrm{N} \mathrm{a}_{2} \mathrm{~K}_{2}\left\{\left[\left(\mathrm{M} \mathrm{o}^{\mathrm{VI}}\right)\right.\right.$. $\left.\left.\mathrm{Mo}^{\mathrm{VI}}{ }_{5} \mathrm{O}_{21}\left(\mathrm{H}_{2} \mathrm{O}\right)_{3}\left(\mathrm{KSO}_{4}\right)\right]_{12}\left[\left(\mathrm{~V}^{\mathrm{IV}} \mathrm{O}\right)_{30}\left(\mathrm{H}_{2} \mathrm{O}\right)_{20}\left(\mathrm{SO}_{4}\right)_{0.5}\right]\right\}$. $\mathrm{ca} 200 \mathrm{H}_{2} \mathrm{O}$

$1 \mathrm{~L}$, the first full lithiation at $0.01 \mathrm{~V}$ versus $\mathrm{Li} / \mathrm{Li}^{+}$

$1 \mathrm{D}$, the first full delithiation at $3 \mathrm{~V}$ versus $\mathrm{Li} / \mathrm{Li}^{+}$.

\section{REFERENCES}

(1) Tarascon, J.-M.; Armand, M. Issues and challenges facing rechargeable lithium batteries. Nature 2001, 414, 359.

(2) Scrosati, B.; Hassoun, J.; Sun, Y.-K. Lithium-ion batteries. A look into the future. Energy Environ. Sci. 2011, 4, 3287-3295.

(3) Palacín, M. R. Recent advances in rechargeable battery materials: a chemist's perspective. Chem. Soc. Rev. 2009, 38, 2565-2575.

(4) Sivakkumar, S. R.; Nerkar, J. Y.; Pandolfo, A. G. Rate capability of graphite materials as negative electrodes in lithium-ion capacitors. Electrochim. Acta 2010, 55, 3330-3335.

(5) Ye, L.; Liang, Q.; Lei, Y.; Yu, X.; Han, C.; Shen, W.; Huang, Z.H.; Kang, F.; Yang, Q.-H. A high performance Li-ion capacitor constructed with Li4Ti5O12/C hybrid and porous graphene macroform. J. Power Sources 2015, 282, 174-178.

(6) Kim, H.; Cho, M.-Y.; Kim, M.-H.; Park, K.-Y.; Gwon, H.; Lee, Y.; Roh, K. C.; Kang, K. A Novel High-Energy Hybrid Supercapacitor with an Anatase $\mathrm{TiO} 2-$ Reduced Graphene Oxide Anode and an Activated Carbon Cathode. Adv. Energy Mater. 2013, 3, 1500-1506.

(7) Aravindan, V.; Cheah, Y. L.; Mak, W. F.; Wee, G.; Chowdari, B. V. R.; Madhavi, S. Fabrication of High Energy-Density Hybrid Supercapacitors Using Electrospun V2O5 Nanofibers with a SelfSupported Carbon Nanotube Network. ChemPlusChem 2012, 77, $570-575$.

(8) Lim, E.; Jo, C.; Kim, H.; Kim, M.-H.; Mun, Y.; Chun, J.; Ye, Y.; Hwang, J.; Ha, K.-S.; Roh, K. C.; Kang, K.; Yoon, S.; Lee, J. Facile Synthesis of Nb2O5@Carbon Core-Shell Nanocrystals with Controlled Crystalline Structure for High-Power Anodes in Hybrid Supercapacitors. ACS Nano 2015, 9, 7497-7505.

(9) Sun, F.; Gao, J.; Zhu, Y.; Pi, X.; Wang, L.; Liu, X.; Qin, Y. A high performance lithium ion capacitor achieved by the integration of a Sn$\mathrm{C}$ anode and a biomass-derived microporous activated carbon cathode. Sci. Rep. 2017, 7, 40990.

(10) Yi, R.; Chen, S.; Song, J.; Gordin, M. L.; Manivannan, A.; Wang, D. High-Performance Hybrid Supercapacitor Enabled by a High-Rate Si-based Anode. Adv. Funct. Mater. 2014, 24, 7433-7439.

(11) Zhang, F.; Zhang, T.; Yang, X.; Zhang, L.; Leng, K.; Huang, Y.; Chen, Y. A high-performance supercapacitor-battery hybrid energy storage device based on graphene-enhanced electrode materials with ultrahigh energy density. Energy Environ. Sci. 2013, 6, 1623-1632.

(12) Yang, M.; Zhong, Y.; Ren, J.; Zhou, X.; Wei, J.; Zhou, Z. Fabrication of High-Power Li-Ion Hybrid Supercapacitors by Enhancing the Exterior Surface Charge Storage. Adv. Energy Mater. 2015, 5, 1500550.

(13) Han, P.; Ma, W.; Pang, S.; Kong, Q.; Yao, J.; Bi, C.; Cui, G. Graphene decorated with molybdenum dioxide nanoparticles for use in high energy lithium ion capacitors with an organic electrolyte. J. Mater. Chem. A 2013, 1, 5949-5954.

(14) Wang, R.; Lang, J.; Zhang, P.; Lin, Z.; Yan, X. Fast and Large Lithium Storage in 3D Porous VN Nanowires-Graphene Composite 
as a Superior Anode Toward High-Performance Hybrid Supercapacitors. Adv. Funct. Mater. 2015, 25, 2270-2278.

(15) Goodenough, J. B.; Park, K.-S. The Li-Ion Rechargeable Battery: A Perspective. J. Am. Chem. Soc. 2013, 135, 1167-1176.

(16) Sun, X.; Radovanovic, P. V.; Cui, B. Advances in spinel Li4Ti5O12 anode materials for lithium-ion batteries. New J. Chem. 2015, 39, 38-63.

(17) Zhang, M.; Zhang, T.; Ma, Y.; Chen, Y. Latest development of nanostructured $\mathrm{Si} / \mathrm{C}$ materials for lithium anode studies and applications. Energy Storage Mater. 2016, 4, 1-14.

(18) Zuo, X.; Zhu, J.; Müller-Buschbaum, P.; Cheng, Y.-J. Silicon based lithium-ion battery anodes: A chronicle perspective review. Nano Energy 2017, 31, 113-143.

(19) Du, D.-Y.; Yan, L.-K.; Su, Z.-M.; Li, S.-L.; Lan, Y.-Q.; Wang, E.B. Chiral polyoxometalate-based materials: From design syntheses to functional applications. Coord. Chem. Rev. 2013, 257, 702-717.

(20) Kawasaki, N.; Wang, H.; Nakanishi, R.; Hamanaka, S.; Kitaura, R.; Shinohara, H.; Yokoyama, T.; Yoshikawa, H.; Awaga, K. Nanohybridization of Polyoxometalate Clusters and Single-Wall Carbon Nanotubes: Applications in Molecular Cluster Batteries. Angew. Chem., Int. Ed. 2011, 50, 3471-3474.

(21) Uematsu, S.; Quan, Z.; Suganuma, Y.; Sonoyama, N. Reversible lithium charge-discharge property of bi-capped Keggin-type polyoxovanadates. J. Power Sources 2012, 217, 13-20.

(22) Ma, D.; Liang, L.; Chen, W.; Liu, H.; Song, Y.-F. Covalently Tethered Polyoxometalate-Pyrene Hybrids for Noncovalent Sidewall Functionalization of Single-Walled Carbon Nanotubes as HighPerformance Anode Material. Adv. Funct. Mater. 2013, 23, 61006105.

(23) Chen, W.; Huang, L.; Hu, J.; Li, T.; Jia, F.; Song, Y.-F. Connecting carbon nanotubes to polyoxometalate clusters for engineering high-performance anode materials. Phys. Chem. Chem. Phys. 2014, 16, 19668-19673.

(24) Nasim Khan, R. N.; Mahmood, N.; Lv, C.; Sima, G.; Zhang, J.; Hao, J.; Hou, Y.; Wei, Y. Pristine organo-imido polyoxometalates as an anode for lithium ion batteries. RSC Adv. 2014, 4, 7374-7379.

(25) Huang, L.; Hu, J.; Ji, Y.; Streb, C.; Song, Y.-F. PyreneAnderson-Modified CNTs as Anode Materials for Lithium-Ion Batteries. Chem.-Eur. J. 2015, 21, 18799-18804.

(26) Yue, Y.; Li, Y.; Bi, Z.; Veith, G. M.; Bridges, C. A.; Guo, B.; Chen, J.; Mullins, D. R.; Surwade, S. P.; Mahurin, S. M.; Liu, H.; Paranthaman, M. P.; Dai, S. A POM-organic framework anode for Liion battery. J. Mater. Chem. A 2015, 3, 22989-22995.

(27) Xie, J.; Zhang, Y.; Han, Y.; Li, C. High-Capacity Molecular Scale Conversion Anode Enabled by Hybridizing Cluster-Type Framework of High Loading with Amino-Functionalized Graphene. ACS Nano 2016, 10, 5304-5313.

(28) Huang, Q.; Wei, T.; Zhang, M.; Dong, L.-Z.; Zhang, A.-M.; Li, S.-L.; Liu, W.-J.; Liu, J.; Lan, Y.-Q. A highly stable polyoxometalatebased metal-organic framework with [small pi]-[small pi] stacking for enhancing lithium ion battery performance. J. Mater. Chem. A 2017, 5, $8477-8483$.

(29) Hu, J.; Diao, H.; Luo, W.; Song, Y.-F. Dawson-Type Polyoxomolybdate Anions (P2Mo18O626-) Captured by Ionic Liquid on Graphene Oxide as High-Capacity Anode Material for Lithium-Ion Batteries. Chem.-Eur. J. 2017, 23, 8729-8735.

(30) Yang, X.-Y.; Wei, T.; Li, J.-S.; Sheng, N.; Zhu, P.-P.; Sha, J.-Q.; Wang, T.; Lan, Y.-Q. Polyoxometalate-Incorporated Metallapillararene/Metallacalixarene Metal-Organic Frameworks as Anode Materials for Lithium Ion Batteries. Inorg. Chem. 2017, 56, 8311-8318.

(31) Zhang, M.; Wei, T.; Zhang, A.-M.; Li, S.-L.; Shen, F.-C.; Dong, L.-Z.; Li, D.-S.; Lan, Y.-Q. Polyoxomolybdate-Polypyrrole/Reduced Graphene Oxide Nanocomposite as High-Capacity Electrodes for Lithium Storage. ACS Omega 2017, 2, 5684-5690.

(32) Ying, H.; Han, W.-Q. Metallic Sn-Based Anode Materials: Application in High-Performance Lithium-Ion and Sodium-Ion Batteries. Adv. Sci. 2017, 4, 1700298.
(33) Hu, J.; Jia, F.; Song, Y.-F. Engineering high-performance polyoxometalate/PANI/MWNTs nanocomposite anode materials for lithium ion batteries. Chem. Eng. J. 2017, 326, 273-280.

(34) Hu, J.; Ji, Y.; Chen, W.; Streb, C.; Song, Y.-F. "Wiring” redoxactive polyoxometalates to carbon nanotubes using a sonicationdriven periodic functionalization strategy. Energy Environ. Sci. 2016, 9, 1095-1101.

(35) Müller, A.; Todea, A. M.; van Slageren, J.; Dressel, M.; Bögge, H.; Schmidtmann, M.; Luban, M.; Engelhardt, L.; Rusu, M. Triangular Geometrical and Magnetic Motifs Uniquely Linked on a Spherical Capsule Surface. Angew. Chem., Int. Ed. 2005, 44, 38573861.

(36) Ni, E.; Uematsu, S.; Quan, Z.; Sonoyama, N. Improved electrochemical property of nanoparticle polyoxovanadate K7NiV13O38 as cathode material for lithium battery. J. Nanopart. Res. 2013, 15, 1732.

(37) Vedrine, J. C.; Praliaud, H.; Meriaudeau, P.; Che, M. Oxidation state and surface segregation of Mo ions in titania catalysts evidenced by ESR, UV and ESCA techniques. Surf. Sci. 1979, 80, 101-109.

(38) Salyn, Y.; Chertkov, A. A.; Padurets, L. N.; Nefedov, V. I. X-ray electron investigation into distribution of electron density in transition element hydrides. Zh. Neorg. Khim. 1974, 19, 1443-1445.

(39) Mazumdar, D.; Govindacharyulu, P. A.; Bose, D. N. Electronic conductivity of AgI using D.C. polarization and charge transfer techniques. J. Phys. Chem. Solids 1982, 43, 933-940.

(40) Yan, B.; Li, M.; Li, X.; Bai, Z.; Yang, J.; Xiong, D.; Li, D. Novel understanding of carbothermal reduction enhancing electronic and ionic conductivity of Li4Ti5O12 anode. J. Mater. Chem. A 2015, 3, 11773-11781.

(41) Zhao, B.; Ran, R.; Liu, M.; Shao, Z. A comprehensive review of Li4Ti5O12-based electrodes for lithium-ion batteries: The latest advancements and future perspectives. Mater. Sci. Eng., R 2015, 98, $1-71$.

(42) Siroma, Z.; Sato, T.; Takeuchi, T.; Nagai, R.; Ota, A.; Ioroi, T. AC impedance analysis of ionic and electronic conductivities in electrode mixture layers for an all-solid-state lithium-ion battery. $J$. Power Sources 2016, 316, 215-223.

(43) Bommier, C.; Luo, W.; Gao, W.-Y.; Greaney, A.; Ma, S.; Ji, X. Predicting capacity of hard carbon anodes in sodium-ion batteries using porosity measurements. Carbon 2014, 76, 165-174.

(44) Wang, Y.; Chen, X.; Liu, Z.; Wu, H.; Zhao, H.; Liu, H.; Zhang, $\mathrm{Y}$. Cycling-induced structure refinement of $\mathrm{MnO}$ nanorods wrapped by $\mathrm{N}$-doped carbon with internal void space for advanced lithium-ion anodes. Appl. Surf. Sci. 2019, 479, 386-394.

(45) Yin, L.; Gao, Y. J.; Jeon, I.; Yang, H.; Kim, J.-P.; Jeong, S. Y.; Cho, C. R. Rice-panicle-like $\gamma$-Fe2O3@C nanofibers as high-rate anodes for superior lithium-ion batteries. Chem. Eng. J. 2019, 356, $60-68$.

(46) Kume, K.; Kawasaki, N.; Wang, H.; Yamada, T.; Yoshikawa, H.; Awaga, K. Enhanced capacitor effects in polyoxometalate/graphene nanohybrid materials: a synergetic approach to high performance energy storage. J. Mater. Chem. A 2014, 2, 3801-3807.

(47) Augustyn, V.; Simon, P.; Dunn, B. Pseudocapacitive oxide materials for high-rate electrochemical energy storage. Energy Environ. Sci. 2014, 7, 1597-1614.

(48) Wang, J.; Polleux, J.; Lim, J.; Dunn, B. Pseudocapacitive Contributions to Electrochemical Energy Storage in $\mathrm{TiO} 2$ (Anatase) Nanoparticles. J. Phys. Chem. C 2007, 111, 14925-14931.

(49) Wang, H.-Y.; Chen, H.-Y.; Hsu, Y.-Y.; Stimming, U.; Chen, H. M.; Liu, B. Modulation of Crystal Surface and Lattice by Doping: Achieving Ultrafast Metal-Ion Insertion in Anatase TiO2. ACS Appl. Mater. Interfaces 2016, 8, 29186-29193.

(50) Koningsberger, D. C.; Mojet, B. L.; van Dorssen, G. E.; Ramaker, D. E. XAFS spectroscopy; fundamental principles and data analysis. Top. Catal. 2000, 10, 143-155.

(51) Panitz, J.-C.; Novák, P.; Haas, O. Raman Microscopy Applied to Rechargeable Lithium-Ion Cells-Steps towards in situ Raman Imaging with Increased Optical Efficiency. Appl. Spectrosc. 2001, 55, $1131-1137$ 
(52) Etacheri, V.; Seisenbaeva, G. A.; Caruthers, J.; Daniel, G.; Nedelec, J.-M.; Kessler, V. G.; Pol, V. G. Ordered Network of Interconnected $\mathrm{SnO} 2$ Nanoparticles for Excellent Lithium-Ion Storage. Adv. Energy Mater. 2015, 5, 1401289.

(53) Wu, D.; Shen, R.; Yang, R.; Ji, W.; Jiang, M.; Ding, W.; Peng, L. Mixed Molybdenum Oxides with Superior Performances as an Advanced Anode Material for Lithium-Ion Batteries. Sci. Rep. 2017, 7, 44697.

(54) Lei, D.; Ye, H.; Liu, C.; An, D.; Ma, J.; Lv, W.; Li, B.; Kang, F.; $\mathrm{He}$, Y.-B. Interconnected Ultrasmall V2O3 and Li4Ti5O12 Particles Construct Robust Interfaces for Long-Cycling Anodes of Lithium-Ion Batteries. ACS Appl. Mater. Interfaces 2019, 11, 29993-30000.

(55) Wen, C. J.; Boukamp, B. A.; Huggins, R. A.; Weppner, W. Thermodynamic and Mass Transport Properties of "LiAl". J. Electrochem. Soc. 1979, 126, 2258-2266.

(56) Bach, S.; Pereira-Ramos, J. P.; Baffier, N. Electrochemical properties of sol-gel Li4/3Ti5/3O4. J. Power Sources 1999, 81-82, 273-276.

(57) Wang, L.; Zhang, Y.; Guo, H.; Li, J.; Stach, E. A.; Tong, X.; Takeuchi, E. S.; Takeuchi, K. J.; Liu, P.; Marschilok, A. C.; Wong, S. S. Structural and Electrochemical Characteristics of Ca-Doped "Flowerlike" Li4Ti5O12 Motifs as High-Rate Anode Materials for LithiumIon Batteries. Chem. Mater. 2018, 30, 671-684.

(58) Rho, Y. H.; Kanamura, K. Li+ ion diffusion in Li4Ti5O12 thin film electrode prepared by PVP sol-gel method. J. Solid State Chem. 2004, 177, 2094-2100.

(59) Xing, Y.; Wang, S.; Fang, B.; Song, G.; Wilkinson, D. P.; Zhang, S. N-doped hollow urchin-like anatase TiO2@C composite as a novel anode for Li-ion batteries. J. Power Sources 2018, 385, 10-17.

(60) Cao, Z.; Wei, B. $\alpha$-Fe2O3/single-walled carbon nanotube hybrid films as high-performance anodes for rechargeable lithium-ion batteries. J. Power Sources 2013, 241, 330-340.

(61) Lou, X.; Lin, C.; Luo, Q.; Zhao, J.; Wang, B.; Li, J.; Shao, Q.; Guo, X.; Wang, N.; Guo, Z. Crystal Structure Modification Enhanced FeNb11O29 Anodes for Lithium-Ion Batteries. ChemElectroChem 2017, 4, 3171-3180.

(62) Park, M.; Zhang, X.; Chung, M.; Less, G. B.; Sastry, A. M. A review of conduction phenomena in Li-ion batteries. J. Power Sources 2010, 195, 7904-7929.

(63) Wen, K.; Xia, M.; Deng, P.; Lv, W.; He, W. A sandwichstructured double-battery device for direct evaluation of lithium diffusion coefficients and phase transition in electrodes of lithium ion batteries. Chem. Eng. Sci. 2019, 200, 80-86.

(64) Li, J.; Xiao, X.; Yang, F.; Verbrugge, M. W.; Cheng, Y.-T. Potentiostatic Intermittent Titration Technique for Electrodes Governed by Diffusion and Interfacial Reaction. J. Phys. Chem. C 2012, 116, 1472-1478.

(65) Ding, N.; Xu, J.; Yao, Y. X.; Wegner, G.; Fang, X.; Chen, C. H.; Lieberwirth, I. Determination of the diffusion coefficient of lithium ions in nano-Si. Solid State Ionics 2009, 180, 222-225.

(66) Levi, M. D.; Aurbach, D. Diffusion Coefficients of Lithium Ions during Intercalation into Graphite Derived from the Simultaneous Measurements and Modeling of Electrochemical Impedance and Potentiostatic Intermittent Titration Characteristics of Thin Graphite Electrodes. J. Phys. Chem. B 1997, 101, 4641-4647.

(67) Ho, C.; Raistrick, I. D.; Huggins, R. A. Application of A-C Techniques to the Study of Lithium Diffusion in Tungsten Trioxide Thin Films. J. Electrochem. Soc. 1980, 127, 343-350.

(68) Southampton Electrochemistry Group. Instrumental Methods in Electrochemistry; Ellis Horwood: England, 1985.

(69) Wu, M.-S.; Wang, M.-J.; Jow, J.-J.; Yang, W.-D.; Hsieh, C.-Y.; Tsai, H.-M. Electrochemical fabrication of anatase $\mathrm{TiO} 2$ nanostructure as an anode material for aqueous lithium-ion batteries. J. Power Sources 2008, 185, 1420-1424.

(70) Tang, K.; Yu, X.; Sun, J.; Li, H.; Huang, X. Kinetic analysis on LiFePO4 thin films by CV, GITT, and EIS. Electrochim. Acta 2011, $56,4869-4875$. 